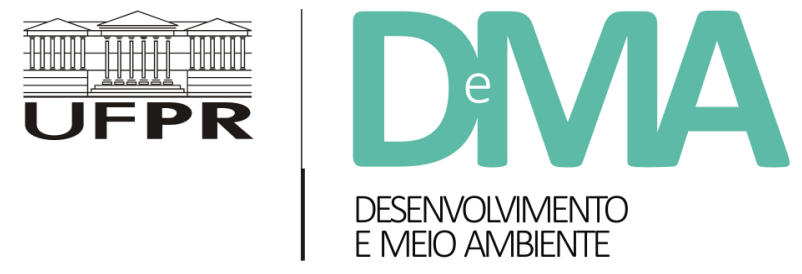

\title{
Aplicação da base ecossistêmica na gestão ambiental de portos
}

\section{Application of the Ecosystem Base in the Environmental Management of Ports}

\section{Lorena Ferreira Goersch ANDRADE ${ }^{1 *}$, Milton Lafourcade ASMUS ${ }^{1}$, Javier García ONETTI², Marinez Eymael Garcia SCHERER ${ }^{3}$}

\author{
${ }^{1}$ Universidade Federal do Rio Grande (FURG), Rio Grande, RS, Brasil. \\ ${ }^{2}$ Universidade de Cádiz (UCA), Cádiz, Espanha. \\ ${ }^{3}$ Universidade Federal de Santa Catarina (UFSC), Florianópolis, Santa Catarina, Brasil. \\ *E-mail de contato: logoersch@gmail.com
}

Artigo recebido em 31 de agosto de 2017, versão final aceita em 21 de fevereiro de 2018.

RESUMO: Este trabalho discute uma proposta de gestão integrada e multidisciplinar para os diferentes setores e serviços portuários do porto de São Francisco do Sul (localizado no litoral Norte do estado de Santa Catarina), Brasil. Foram utilizados fatores das atividades portuárias relacionados ao modelo Drivers-Pressure-State-ImpactResponse (DPSIR), objetivando o estabelecimento de um suporte de informação com Base Ecossistêmica necessário a um Sistema de Gestão Ambiental Portuária, aplicado ao estudo de caso. Este suporte de informação prevê a caracterização dos ecossistemas e serviços ecossistêmicos existentes na área de estudo, a identificação das macroatividades presentes no porto e a caracterização dos aspectos ambientais gerados pelas macroatividades do porto, permitindo a identificação dos aspectos ambientais significativos e a análise dos principais impactos ambientais identificados, além da elaboração de uma proposta de recomendações de estratégias para gestão ao porto. Os aspectos ambientais significativos para o porto de São Francisco do Sul foram as descargas e vazamentos para a água; os lançamentos de efluentes para os sedimentos marinhos; a geração de resíduos sólidos; as interações que geram mudanças estruturais nos ecossistemas marinhos; e a interação com a comunidade portuária local (em meio terrestre). Foram realizadas sugestões de táticas de gestão direcionadas aos impactos específicos causados por estes aspectos, mostrando como esta é uma metodologia aplicável de forma concisa e prática, correspondendo aos princípios básicos da Gestão com Base Ecossistêmica (GBE), de atender aos setores econômicos, ambientais e sociais a partir dos serviços ecossistêmicos, levando em consideração as atividades humanas e a importância dos ecossistemas.

Palavras-chave: serviços ecossistêmicos; gestão com base ecossistêmica; porto de São Francisco do Sul; Baía da Babitonga. 
ABSTRACT: This paper discusses a proposal for integrated and multidisciplinary management for the different port sectors and services of the port of São Francisco do Sul (located in the North coast of Santa Catarina State), Brazil. Factors of port activities related to the Drivers-Pressure-State-Impact-Response (DPSIR) model were used, aiming at the establishment of an information support Ecosystem-Based needed for a Port Environmental Management System, applied to this case study. This information support provides a process for the characterization of ecosystems and ecosystem services in the study area; the identification of macro activities present in the port and characterization of the environmental aspects generated by the macro activities of the port; allowed the identification of significant environmental aspects and analysis of the main environmental impacts identified; besides preparing a recommendation proposal of strategies for the port management. The significant environmental aspects for the port of São Francisco do Sul were the discharges and leaks to the water; the effluent releases to marine sediments; the solid waste generation; the interactions that generate structural changes in marine ecosystems; and the interaction with the local port community. We came with suggestions of management tactics towards the specific impacts caused by these aspects, showing how this is a methodology applicable in a concise and practical way, corresponding to Ecosystem-Based Management (EBM) basic principles, to attend the economic, environmental and social sectors from the ecosystem services taking into account human activities and the importance of ecosystems.

Keywords: ecosystem services; ecosystem-based management; port of São Francisco do Sul; Babitonga Bay.

\section{Introdução}

A Gestão Ambiental Portuária (GAP) no Brasil ainda ocorre de maneira pouco consistente e segmentada, nos deixando numa posição bem abaixo do ideal em termos globais (Porto \& Teixeira, 2002; Lourenço, 2012). Seguindo o exemplo de diversos países que programaram diretrizes de GAP, o Brasil definiu a Portaria SEP (104, de 2009) quanto à necessidade de um sistema de gestão ambiental e segurança do trabalho aplicado aos portos (Asmus et al., 2015).

Alguns dos impactos resultantes da dinâmica de uso e ocupação do entorno de um porto (ocupação do retroporto e modais de transporte, por exemplo) pelas atividades portuárias envolvem a contaminação de corpos de água adjacentes pela falta de saneamento; modificação de hidrodinâmica e do leito marinho por atividades de dragagem; material contaminante e orgânico em suspensão; e a contaminação por meio de organismos exóticos acompanhantes da água de lastro de navios (Barragán, 2010).

Esse trabalho considerou a Gestão Ambiental com Base Ecossistêmica como uma possível alternativa para a gestão de portos no Brasil e no mundo. A gestão com base ecossistêmica deve levar em consideração o ecossistema como um todo, definido em termos locais, biofísicos, socioeconômicos, culturais e administrativos. Deve ainda se pautar no desenvolvimento de um processo integrado de planejamento e gestão, abrangendo a complexidade, a transdisciplinaridade e a dinâmica dos sistemas naturais. Seu alcance de interesses e metas reconhece objetivos, valores e limites, incluindo o ser humano, num processo de fácil entendimento e implementação de forma consistente para diferentes grupos sociais (Slocombe, 1998).

Segundo a Avaliação Ecossistêmica do Milênio (MEA, 2003), os tomadores de decisão precisam 
entender os efeitos múltiplos de qualquer gestão ou alteração de políticas nos ecossistemas, entender a necessidade de examinar as consequências de mudanças aplicadas aos ecossistemas e compreender os fatores que causam as mudanças nos serviços de ecossistemas, tópicos essenciais na projeção de intervenções que garantam impactos positivos e minimizem os negativos.

As diferenças em relação às metas de gestão, função dos ecossistemas e participação humana podem afetar a extensão da abordagem ecossistêmica nos planos de gestão e, talvez, tanto a academia quanto o setor político ainda careçam de uma clara abordagem ou ferramentas para uma gestão com base ecossistêmica (Arkemal et al., 2006). Nesse sentido, a proposta deste estudo é fundamentada na necessidade de uma ferramenta específica de gestão, a partir de uma proposta metodológica que usa o conceito de base ecossistêmica para o setor portuário associado a um modelo DPSIR (do inglês Drivers, Pressures, State, Impacts, Response) (EEA, 1999), para gerar um caso de análise capaz de ser referenciado em outros portos, levando em consideração os ecossistemas, os serviços ecossistêmicos e as condições sociais, ecológicas e econômicas dos mesmos. Para tal, selecionou-se um estudo de caso a ser desenvolvido no porto de São Francisco do Sul, localizado ao norte do estado de Santa Catarina (SC), Brasil.

São Francisco do Sul é um porto caracterizado como de múltiplo uso, sendo o maior terminal portuário público de $\mathrm{SC}$ em relação à movimentação de cargas. Atualmente ocupa a sétima posição entre os portos públicos brasileiros no ranking nacional IDA (Índice de Desempenho Ambiental), divulgado pela ANTAQ (ANTAQ, 2016), que visa à monitoria do atendimento da legislação ambiental e dos impactos ambientais causados pelas operações portuárias. $\mathrm{O}$ município de São Francisco do Sul (e toda a região da baía da Babitonga) está inserido em áreas de proteção ambiental, gerando preocupações quanto à manutenção destas e seus ecossistemas (Lima, 2016). Apesar do apoio de grande parte de empresários, que apelam para o crescimento econômico e para a geração de empregos, há resistência da comunidade quanto à implementação de novos portos na região. Destacam-se nessa questão os serviços ecossistêmicos afetados, as atividades, os aspectos e impactos ambientais, além dos indicativos de suporte para o Sistema de Gestão Ambiental (SGA) do porto.

\section{Metodologia}

A metodologia empregada consiste na adaptação de um modelo de gestão com base ecossistêmica desenvolvido por Asmus et al. (2015) e Scherer et al. (2015) e também descrito em García-Onetti (2017) e García-Onetti et al. (2018), aplicado no porto de São Francisco do Sul, estado de Santa Catarina. Ela é baseada numa avaliação das atividades portuárias relacionadas à atividade humana, fundamentada nos ecossistemas e seus serviços ecossistêmicos presentes na área de estudo. Os autores definem as principais macroatividades de um porto, os aspectos ambientais mais importantes, os critérios de significância e desenvolvem quadros e matrizes de base. Estas definições e matrizes são organizadas a partir de vasta pesquisa bibliográfica e iniciativas de instituições internacionais, europeias e brasileiras, relacionando as atividades portuárias habituais em portos marítimos, que foram agrupadas em macroatividades, e os aspectos ambientais 
gerados por elas. Com isso, é possível identificar os aspectos significativos e seus potenciais impactos ambientais, a fim de permitir a proposta de indicativos de gestão adequados às necessidades específicas de determinado porto. A proposta da metodologia envolve a possível aplicação destes quadros e matrizes em diferentes portos, facilitando a gestão ao proporcionar a aplicação de medidas específicas às necessidades de cada um.

Inicialmente foram identificadas as Unidades Ambientais presentes na área de estudo por meio de análise visual de imagens de satélites e levantamento bibliográfico. Importante ressaltar que, para este trabalho, Unidades Ambientais são entendidas, conforme García-Onetti (2017), como sendo estruturas organizadas, geograficamente capazes de prover, mediante suas funções, um fluxo de serviços naturais ou antrópicos, e formadas por elementos vivos e não vivos. Assim, consideram-se Unidades Ambientais tanto os ecossistemas naturais como aqueles antrópicos e seus serviços ecossistêmicos.

As Unidades Ambientais identificadas foram organizadas numa matriz de Serviços Ecossistêmicos, que serviu de base de informação para a continuidade do trabalho. Nela foram classificados os serviços ecossistêmicos de suporte/provisão/ regulação/cultural de cada Unidade Ambiental, assim como seus usos/benefícios e atores beneficiados, baseados em Scherer \& Asmus (2016). Em seguida, foram identificadas as atividades portuárias presentes em São Francisco do Sul, dentre as 21 macroatividades propostas na metodologia. Segundo Scherer et al. (2015), elas proveem informações essenciais, já que eventuais mudanças no mapa de atividades portuárias mudarão também as pressões que o porto gera sobre o meio ambiente. Cada atividade portuária gera pressões específicas sobre o meio ambiente. No entanto, essa relação depende do modo como as atividades são desenvolvidas em cada porto considerado. Na sequência, foram caracterizados os aspectos ambientais do porto dentre os doze aspectos-chave apresentados na metodologia. Os aspectos ambientais são fundamentais para apontar os possíveis impactos ambientais que o porto poderia gerar, auxiliando os indicativos de ações para gestão adequados às suas carências e necessidades. Para a identificação dos aspectos ambientais significativos, utilizaram-se como ferramenta de apoio sete critérios de significância, estabelecidos a partir de embasamento teórico sobre a atividade portuária em geral, apresentados em Scherer et al. (2015) como:

1. O aspecto ambiental é relacionado a muitas atividades do porto?;

2. O aspecto ambiental representa a perda ou ganho de um número relevante de serviços ecossistêmicos e ambientais?;

3. O aspecto ambiental afeta ou pode afetar elementos estratégicos especialmente relevantes para o município em que o porto está inserido?;

4. $\mathrm{O}$ aspecto ambiental tem um histórico de acidentes registrado? Supõe um risco excepcional de acidente para o meio ambiente e para a segurança e a saúde da sociedade e dos trabalhadores?;

5. O aspecto acumula reclamações dos cidadãos e/ou dos trabalhadores do Porto? Supõe um assunto prioritário na agenda local do Município de São Francisco do Sul?;

6. O aspecto tem alcance multiescalar?; 
7. O aspecto é identificado como significativo pelo próprio porto ou pelos arrendatários?

Os resultados do Critério 1 foram provenientes da aplicação de quadro que relaciona as Macroatividades e os Aspectos Ambientais do porto. Eles proporcionaram a identificação dos aspectos com maior número de atividades envolvidas. Os resultados do Critério 2 derivaram da aplicação de quadro que relaciona os Aspectos Ambientais e os Serviços Ecossistêmicos presentes. Eles permitiram a identificação dos aspectos que mais impactam negativamente os ecossistemas. Para responder aos critérios de 3 a 7, foram utilizadas as informações obtidas por meio de pesquisa bibliográfica, visita de campo e entrevista com o assessor de engenharia e meio ambiente do porto, apresentadas em quadro de Significância Ambiental do porto de SFS.

$\mathrm{O}$ quadro de Macroatividades versus (vs.) Aspectos Ambientais é uma matriz que identificou a relação causa-efeito sobre como as macroatividades portuárias interagem com os aspectos ambientais identificados no porto, se existem e se foram ou não características para o porto de São Francisco do Sul. Ele foi preenchido como 1, para quando a atividade do porto se relaciona ao aspecto com relação evidente, e como 0, quando a atividade do porto não gera esse aspecto ambiental ou quando existe uma pequena relação causa-efeito entre atividade e aspecto, não sendo característica para o porto.

A seleção dos Aspectos Ambientais Significativos (AAS) exigiu um número de corte. Os aspectos com valor no somatório acima de 50\%+1 da pontuação de referência foram considerados significativos. Os valores significativos assumiram o valor de 1 , e os restantes assumiram o valor de 0 .
O quadro de Aspectos Ambientais vs. Serviços Ecossistêmicos representou uma matriz que auxiliou na identificação de quais foram os ecossistemas impactados e como os aspectos ambientais induziram a perdas ou ganhos de serviços ecossistêmicos. O preenchimento foi feito com os valores: -1, quando o aspecto ambiental gera um impacto negativo sobre o serviço ambiental, provocando sua redução; +1 , quando o aspecto ambiental gera um impacto positivo sobre o serviço ambiental, provocando sua melhoria; e 0, quando o aspecto ambiental não impacta significativamente sobre o serviço ambiental.

O quadro de Significância Ambiental representou a matriz que mostra os resultados da aplicação dos critérios de significância para cada aspecto ambiental chave presente no porto de São Francisco do Sul. Sempre que um dos aspectos ambientais atendeu algum dos sete critérios definidos, recebeu um valor 1 e, caso não, 0 . Com a somatória, obtiveram-se os Aspectos Ambientais Significativos (AAS), sendo que os quadros seguintes indicaram os principais impactos causados às unidades ambientais e os respectivos serviços ecossistêmicos afetados pela atividade portuária.

A última matriz representou toda informação gerada até então, de forma organizada e seguindo o marco conceitual de Força Motriz-Pressão-Estado-Impacto-Resposta (em inglês, Driver-Pressure-State-Impact-Response ou Modelo DPSIR), adaptado para o Porto de São Francisco do Sul. A coluna de Força Motriz compilou todas as atividades responsáveis para cada AAS. A coluna de Pressão reuniu cada um dos AAS. A coluna seguinte mostrou a avaliação quantitativa de cada AAS. A coluna de Estado apresentou os serviços ecossistêmicos afetados por cada AAS. A coluna de impactos significativos listou a caraterização dos ganhos e perdas de 
serviços ecossistêmicos associados a cada AAS. E, finalmente, a coluna que representou o Indicativo de Resposta enumerou recomendações baseadas na informação de cada coluna anterior que permitam um melhor funcionamento das atividades, diminuam sua pressão sobre o meio ambiente, proporcionem um maior controle do seu estado e reduzam a perda de serviços ecossistêmicos. A Figura 1 demonstra a conexão da Matriz de Serviços Ecossistêmicos e a Matriz DPSIR.

\section{Caracterização da área de estudo}

O município de São Francisco do Sul compreende sistemas ambientais marinhos, estuarinos e fluviais, possuindo seu litoral dividido entre a área litoral banhada pelo oceano Atlântico e a área que abriga a baía estuarina da Babitonga, maior baía do estado de Santa Catarina. Além de dezenas de ilhas, possui uma considerável faixa de mata atlân- tica preservada, destacando-se os ecossistemas de restinga e manguezal.

O porto de São Francisco do Sul está localizado na porção leste da baía da Babitonga, entre as coordenadas $26^{\circ} 14^{\prime} \mathrm{S}$ e $48^{\circ} 42^{\prime} \mathrm{W}$, litoral Norte do estado de Santa Catarina. Ele foi oficialmente inaugurado em 1955 e é gerenciado pelo estado de Santa Catarina desde então, pela Autarquia APSFS. Segundo Berger (2006), a área de influência do porto abrange as regiões Norte e Nordeste do estado, o Vale do Rio Itajaí e o Planalto Serrano. Além da prática portuária como principal atividade econômica do município, destaca-se em segundo plano o turismo na área (Mancini, 2007).

São Francisco do Sul possui 498,6 km² de área e população de 42.520 habitantes, de acordo com o IBGE (2010), e é a cidade mais antiga do estado, com localização privilegiada, a apenas $40 \mathrm{~km}$ de distância de Joinville, maior município de SC. A navegação está intimamente associada à história da cidade e sua população. Segundo Cabral (2011),

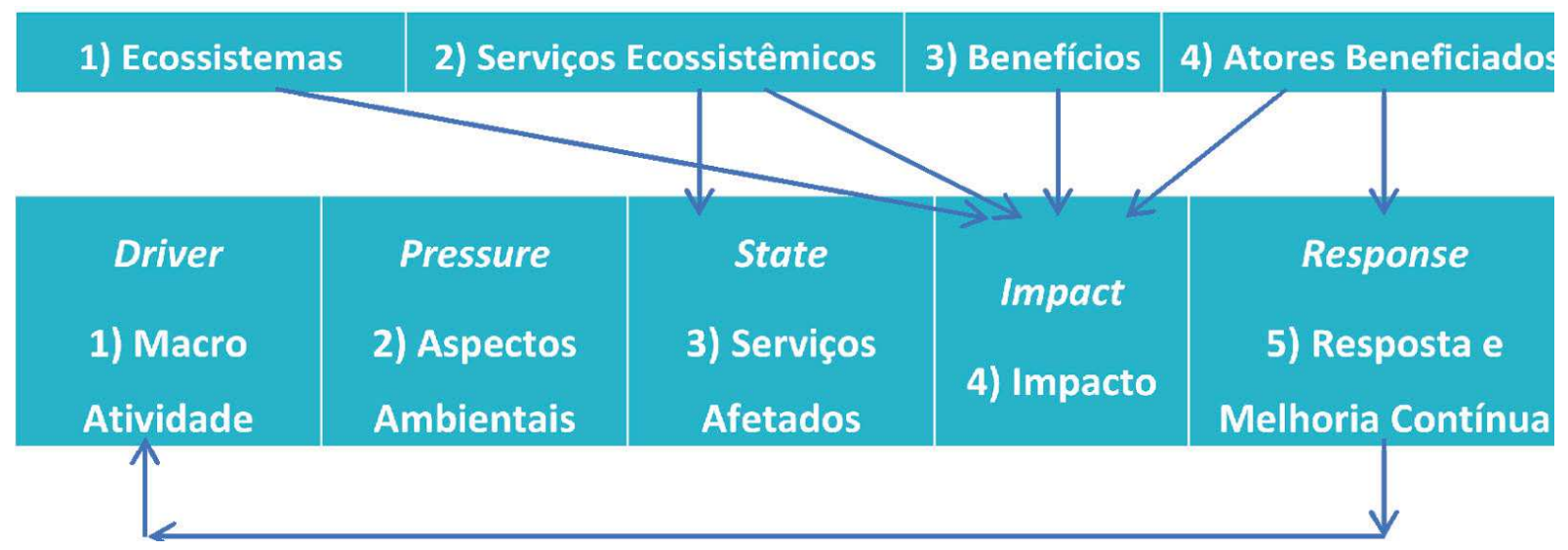

FIGURA 1 - Conexão entre a matriz de Serviços Ecossistêmicos e a Matriz DPSIR. FONTE: Adaptado de Scherer et al. (2015). 
"é impraticável não mencionar o porto ao se referir ao município", pois São Francisco do Sul apresenta elevado grau de dependência em relação ao porto, visto que, ao contrário de cidades portuárias como Rio Grande e Rio de Janeiro, o município não desenvolveu a atividade industrial, tendo suas atividades econômicas determinantes nos ramos portuário, comércio, serviços, pesca e turismo, com o porto e os serviços por ele gerados à frente de quaisquer outras atividades. Além disso, o porto está localizado numa região de importância ecológica, a baía da Babitonga, onde estão inseridas diversas áreas de proteção ambiental, sendo, por isso, necessário um cuidado redobrado com as operações portuárias na região. O porto de SFS responde ao IBAMA quanto às suas questões ambientais.

\section{Resultados}

\subsection{Unidades ambientais}

A poligonal que delimita a Área do Porto Organizado (APO) de São Francisco do Sul está sendo atualizada e encontra-se em trâmite no Ministério dos Transportes, Portos e Aviação para ser publicada em Diário Oficial. A poligonal proposta apresenta uma área muito maior que a anterior, incluindo a área de bota-fora de sedimentos de dragagem (meio marinho) e outras regiões de influência do porto. São identificadas aqui as 10 Unidades Ambientais existentes na APO e no seu entorno, situadas em uma

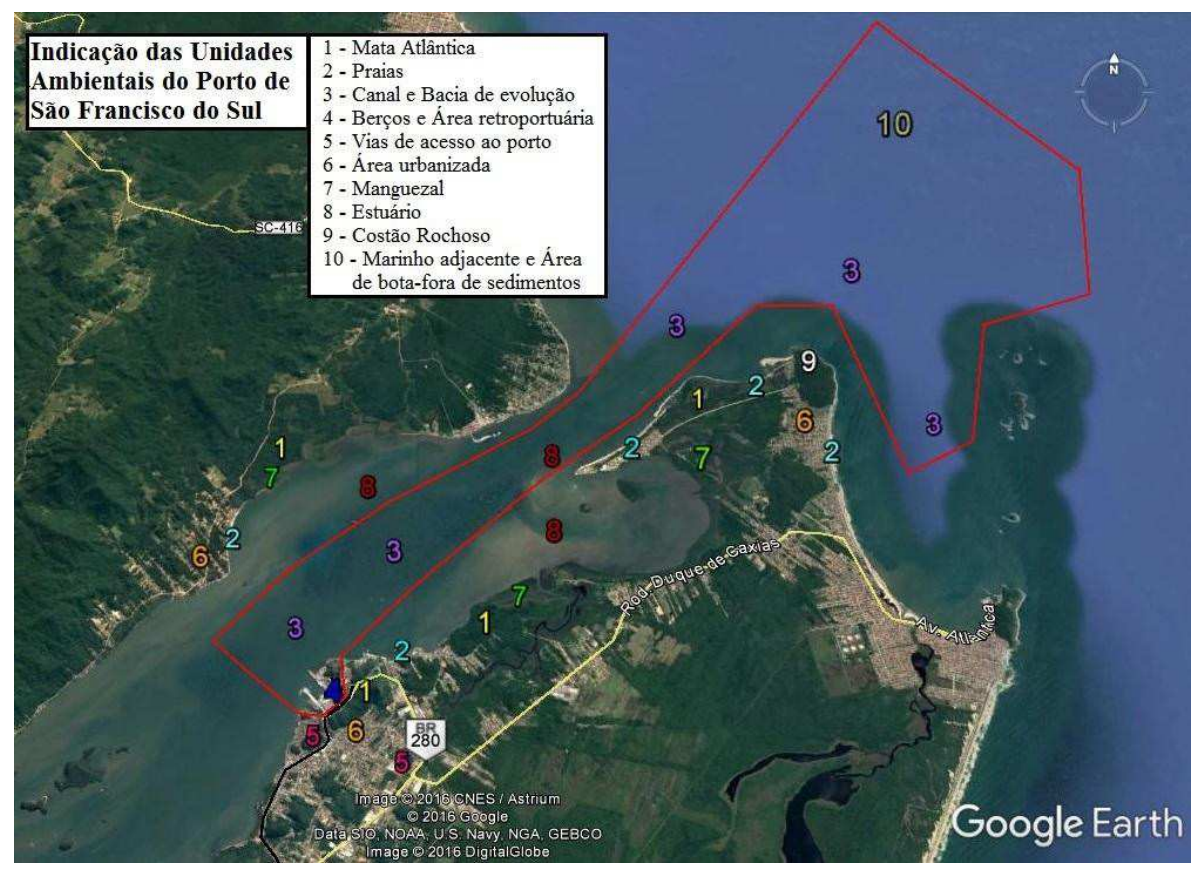

FIGURA 2 - Unidades Ambientais do porto de São Francisco do Sul e seu entorno. O polígono em vermelho representa a Área do Porto Organizado (APO).

FONTE: Elaboração própria. 
área que comporta tanto a poligonal do porto atual como a poligonal proposta para o futuro (Figura 2).

As Unidades Ambientais são descritas a seguir e apresentadas na Tabela 1 (Matriz de Unidades Ambientais e Serviços Ecossistêmicos) com seus serviços ecossistêmicos, usos e benefícios e atores beneficiados. Ressalta-se que para este trabalho considerou-se como atores beneficiados aqueles de grupos sociais humanos (ex.: pescadores, comunidade local, turismo, etc.), assim como elementos da fauna e da flora.

\subsubsection{Mata Atlântica}

A porção remanescente de Mata Atlântica que compreende o município de São Francisco do Sul no estado de Santa Catarina é classificada predominantemente como Floresta Ombrófila Densa e ainda há $45 \%$ de floresta remanescente no município, nas formas de mata, mangue e restinga (INPE, 2016). Esta unidade ambiental foi identificada tanto na Área do Porto Organizado como na área de influência do porto, identificada como aquela adjacente à Área do Porto Organizado (APO) em, no máximo, 3 quilômetros.

\subsubsection{Praias}

As praias são formações derivadas do transporte e da deposição de sedimentos produzidos pela erosão das costas rochosas devido ao movimento das ondas e marés na linha costeira dos oceanos (Press et al., 2006). Ambientes aparentemente homogêneos, as praias são muito dinâmicas e podem apresentar características físicas diferentes (reflexivas, dissipativas [Hesp \& Short, 1999], por exemplo), dependendo de diversos fatores, como a proximidade de cada uma de rios e costões rochosos, do tipo de vegetação, do tipo de clima, da inclinação da praia, do regime de ondas e marés. Neste estudo, foram consideradas as praias: dos Ingleses, Bonita, Figueira, Paulas, Calixto, Varizes, Capri, Forte, Ubatuba e Itaguaçu.

\subsubsection{Canal e bacia de evolução do Porto}

Canal de acesso do porto e áreas de evolução das embarcações com formação e localização compatíveis com a batimetria local, composição do padrão hidrológico e dragagens de manutenção. $\mathrm{O}$ canal de acesso do porto de São Francisco do Sul tem 17,2 km de extensão, com 150 m de largura, 13 $m$ de calado, possui ampla bacia de evolução, com amplitude de maré de 2 m e 5 áreas de fundeadouros oficiais (APSFS, 2016b). A bacia de evolução possui diâmetro de $615 \mathrm{~m}$ e profundidade de $14 \mathrm{~m}$ (Costa, 2011), encontra-se adjacente aos berços de atracação e permite que o cais receba embarcações com até $276 \mathrm{~m}$ de comprimento (LABTRANS, 2012).

\subsubsection{Berços e área retroportuária}

Os berços são a estrutura física de acostamento das embarcações no sistema portuário para atividades de carga-descarga e de transbordo. O Porto de São Francisco do Sul apresenta um cais acostável de $1.530 \mathrm{~m}$ de extensão, com seis berços de atracação: 101, 102, 103, 201, 301 interno e 301 externo, todos com $14 \mathrm{~m}$ de profundidade (LABTRANS, 2012). Atualmente, a APSFS aguarda posicionamento do Ministério dos Transportes, Portos e Aviação para autorização da construção do berço 401. 
A área retroportuária representa o espaço terrestre adjacente ao cais de atracação, caracteristicamente ocupado por armazéns, pátios, vias de circulação de mercadorias, maquinário de apoio, oficinas, áreas de vivência e segurança e setores administrativos. Na retroárea do Porto de SFS, destacam-se três terminais de grandes empresas que compõem o corredor de exportação instalado na zona primária do Porto: Terlogs, Bunge e CIDASC.

\subsubsection{Vias de acesso ao porto}

São consideradas aqui as vias terrestres de acesso ao Porto, por meios rodoviário e ferroviário. A principal ligação rodoviária do município é pela BR-280, que liga São Francisco do Sul a Joinville, maior cidade do estado, localizada a apenas 40 $\mathrm{km}$ de distância. Segundo LABTRANS (2012), a BR-280 intercepta a BR-101 a $34 \mathrm{~km}$ do porto e a BR-116 em Mafra (SC) e possui uma capacidade de tráfego média, que tende a saturar nos períodos de veraneio, além do tráfego intenso regular do fluxo entre os municípios de Joinville e Jaraguá do Sul.

O transporte ferroviário do porto de São Francisco do Sul é mantido pela ALL (América Latina Logística). Ele ocorre por meio da estrada de ferro 485, ligando o município até Mafra, que tem acesso à rede ferroviária de São Paulo, Rio Grande do Sul, Paraná, entre outras. Há diversos conflitos relacionados com as operações ferroviárias e com o trânsito de veículos e pedestres na cidade, especialmente no cruzamento com as vias urbanas, pois a ferrovia atravessa a cidade até chegar ao porto, gerando transtorno e congestionamentos.

\subsection{6. Área Urbana}

São as áreas urbanas de São Francisco do Sul adjacentes à Área do Porto Organizado. Como já foi mencionado, SFS é vizinho de Joinville, o maior município do estado, o que afeta diretamente suas relações socioeconômicas. Além disso, devido à história do município e do porto, destaca-se que 92,8\% da população está concentrada na zona urbana (IBGE, 2010). A atividade portuária é a maior fonte de renda do município, influenciando diretamente o cotidiano urbano, já que SFS apresenta sua orla como fator determinante para a ocupação voltada ao turismo e ao lazer, assim como diversas atrações históricas, culturais e ecológicas de destaque, que devem ser levadas em consideração na relação porto-cidade (LABTRANS, 2012).

\subsubsection{Manguezal}

Manguezais são ecossistemas costeiros, de transição entre os ambientes terrestre e marinho, característicos de regiões tropicais e subtropicais, suscetíveis ao regime das marés (Schaeffer-Novelli, 1995). Possuem uma vegetação típica, capaz de desenvolvimento em áreas alagadas salobras, são importantes berçários naturais e habitats de espécies, considerados zonas de alta produtividade biológica por apresentarem integrantes em todos os segmentos da cadeia alimentar. A unidade ambiental manguezal na área adjacente ao porto de São Francisco do Sul está inserida no ecossistema da Mata Atlântica, estando aqui destacada devido à sua importância e à sua fragilidade na área de estudo, considerada por Cremer et al. (2006) a última grande formação de manguezais do hemisfério sul. 


\subsubsection{Estuário}

Os estuários são ambientes únicos, com características físicas e químicas específicas, por exemplo, salinidade, temperatura, etc. Eles apresentam alta produtividade e baixa diversidade de espécies. Também são zonas de abrigo, reprodução e berçário para diversas espécies em um determinado período de seu desenvolvimento e, portanto, de suma importância para a manutenção das zonas costeiras. Apesar de abranger outras unidades ambientais em seu interior, neste caso a área considerada é referente ao estuário como corpo d'água, envolvendo toda a região a partir do início da baía da Babitonga e seus respectivos serviços ecossistêmicos.

\subsubsection{Costão rochoso}

Costões rochosos são ecossistemas costeiros de transição, formados por rochas, localizados entre os meios terrestre e aquático e de grande riqueza e diversidade biológica. É considerado aqui o afloramento rochoso identificado na região do Forte Marechal Luz, extremo nordeste do município, o qual pertence ao Complexo São Francisco do Sul, segundo Vieira (2016), para denominar toda a área de costões rochosos do município. Os costões são ambientes fundamentais para a manutenção de outros ecossistemas, de grande importância para a morfologia das praias, além de exercerem função de fornecer alimento, abrigo físico e habitat para muitas espécies.

\subsubsection{Marinho adjacente e área de bota-fora de sedimentos}

A unidade marinha inicia com as praias oceânicas a partir da isóbata de $10 \mathrm{~m}$ sugerida pelo
Plano Nacional de Gerenciamento Costeiro. O porto possui diversos programas de monitoramento, destacando-se, para esta unidade ambiental, o de sedimentos marinhos e o de cetáceos, de quelônios e de biomonitores. A área de bota-fora dos sedimentos oriundos de dragagem de manutenção e aprofundamento do porto de São Francisco do Sul está localizada na área marinha adjacente, oceano Atlântico.

\subsection{Macroatividades vs. aspectos ambientais}

A matriz apresentada na Tabela 2 relaciona as macroatividades portuárias aos aspectos ambientais. As macroatividades em evidência no porto de SFS foram: dragagem de manutenção; tráfego terrestre; carga, descarga e armazenamento de granéis sólidos; e funcionamento anormal (emergencial) do porto. Devido ao fato de exercerem maior influência sobre os aspectos ambientais, estas foram consideradas as atividades com maior potencial de gerar danos ambientais, portanto, devem ser monitoradas com especial atenção.

Os aspectos ambientais relacionados com o maior número de atividades são definidos assim pelo somatório por colunas da matriz. Para o porto de São Francisco do Sul, foram: descargas e vazamentos para a água; geração de resíduos sólidos; consumo de recursos e interação com a comunidade portuária e local (meio terrestre). Embora estejam associados ao maior número de atividades, estes aspectos não necessariamente são os que geram os impactos ambientais mais significativos. 
TABELA 1 - Matriz de Unidades Ambientais e Serviços Ecossistêmicos do porto de São Francisco do Sul.

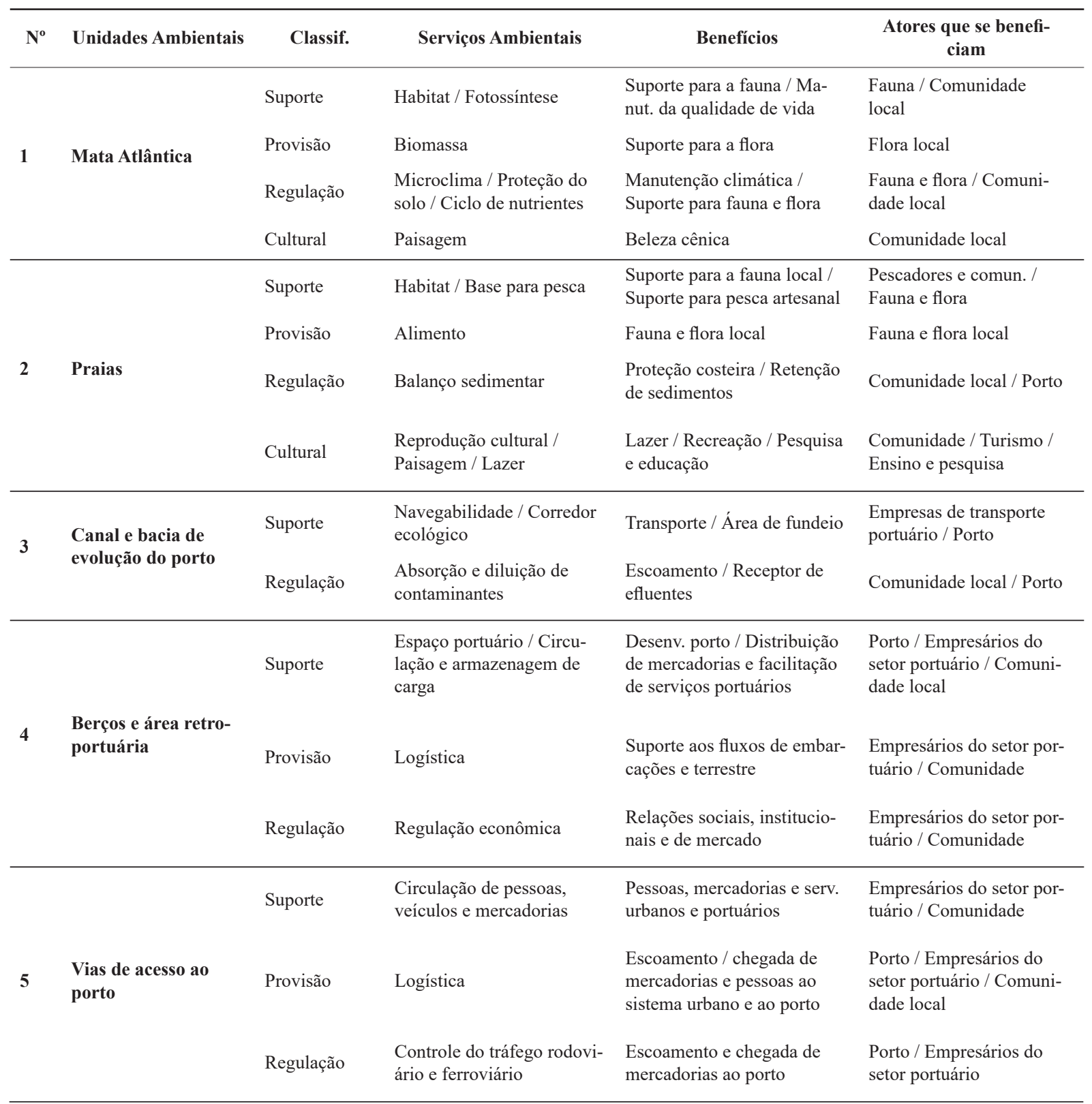


Suporte Infraestrutura

6

Área urbanizada

Provisão

Regulação

Cultural

Suporte

Produção de mat. orgânica /

$7 \quad$ Manguezal

Provisão

Regulação

Cultural

Proteção da linha de costa /

Produção de mat. orgânica

Suporte

Provisão

8

Estuário

Regulação

Berçário de espécies /

Cultural

\begin{tabular}{lll}
\hline & Suporte & Diversidade de habitats \\
& Provisão & $\begin{array}{l}\text { Estoque de mariscos } / \\
\text { Estoque pesqueiro }\end{array}$ \\
& Regulação & Abrigo físico \\
& Cultural & Paisagem / Área de lazer
\end{tabular}

\begin{tabular}{|c|c|c|c|c|c|}
\hline \multirow{3}{*}{10} & \multirow{3}{*}{$\begin{array}{l}\text { Marinho adjacente e } \\
\text { área de bota-fora de } \\
\text { sedimentos }\end{array}$} & Suporte & $\begin{array}{l}\text { Navegabilidade / receptor } \\
\text { de efluentes /Habitat / } \\
\text { Espaço para descarte de } \\
\text { material de dragagem }\end{array}$ & $\begin{array}{l}\text { Transporte / Passagem, } \\
\text { reprodução, alimentação da } \\
\text { fauna marinha / Local para } \\
\text { "estocagem de sedimentos" }\end{array}$ & $\begin{array}{l}\text { Porto / Emp. do setor } \\
\text { portuário / Comunidade } \\
\text { Setor pesqueiro / Turismo } \\
\text { / Fauna e flora }\end{array}$ \\
\hline & & Provisão & $\begin{array}{l}\text { Estoque de sedimentos / } \\
\text { Estoque pesqueiro }\end{array}$ & Pesca & $\begin{array}{l}\text { Porto / Emp. do setor } \\
\text { port. e pesq. / Comun. }\end{array}$ \\
\hline & & Regulação & $\begin{array}{l}\text { Fluxo de sedimentos / } \\
\text { Absorção e diluição de } \\
\text { contaminantes }\end{array}$ & $\begin{array}{l}\text { Diluição de contaminantes } \\
\text { do porto }\end{array}$ & Porto / Comunidade local \\
\hline
\end{tabular}

FONTE: Elaboração própria, com base em Asmus et al. (2015), Scherer et al. (2015) e Scherer \& Asmus (2016).
Serviços urbanos

Econômica administrativa e jurídica / Serv. urbanos

Reprodução cultural e patrimonial

Habitat / Fotossíntese

Berçário de espécies /

Alimentos / Biomassa

Ciclagem de nutrientes

Paisagem

Habitat / Navegabilidade

Alimentos

Abrigo / Controle hídrico

Reprod. Cult. / Paisagem

Habitação, mobilidade, acessibilidade aos serviços / Bem-estar social

Acesso à agua, energia, coleta de resíduos, saúde, educação / Bem-estar social

Relações sociais e institucionais

Manutenção da identidade cultural

Suporte para a fauna / Manut. da qualidade de vida

Pesca artesanal / Suporte para a fauna

Retenção de sedimentos / Erosão / Proteção da floresta

Beleza cênica

Suporte para a fauna /

Transporte

Passagem, reprod., proteção

e alimentação da fauna /

Suporte para a pesca

Escoamento / Receptor de sedimentos e efluentes sanitários e industriais

Lazer / Turismo / Recreação

Suporte para a fauna local

Coleta de marisco / Pesca artesanal

Segurança à navegação $\mathrm{e}$ fundeio

Lazer / Mergulho / Pesquisa e educação / Pesca recreativa

Transporte / Passagem, fauna marinha / Local para Espaço para descarte de Estoque de sedimentos / Fluxo de sedimentos / Absorção e diluição de contaminantes
Comunidade local /

Turismo / Setor governamental / Porto

Cooperativas locais / Comunidade local / Porto

Comunidade local / Porto

Comunidade local

Fauna / Comunidade

local / Pesca

Fauna / Pesca

Comunidade Local /

Pesca

Comunidade local

Porto / Comunidade local

/ Fauna e flora

Fauna local / Pesca

Porto / Indústrias

Comunidade local /

Turismo

Fauna e Flora local

Comunidade / Pesca / gastronomia

Pesca / Comunidade

Comunidade local / Instituições de ensino

Porto / Emp. do setor portuário / Comunidade Setor pesqueiro / Turismo

Porto / Emp. do setor port. e pesq. / Comun.

Porto / Comunidade local 
TABELA 2 - Aspectos ambientais vs. Macroatividades no porto de São Francisco do Sul, com destaque (em cinza) aos aspectos que se relacionam com o maior número de atividades.

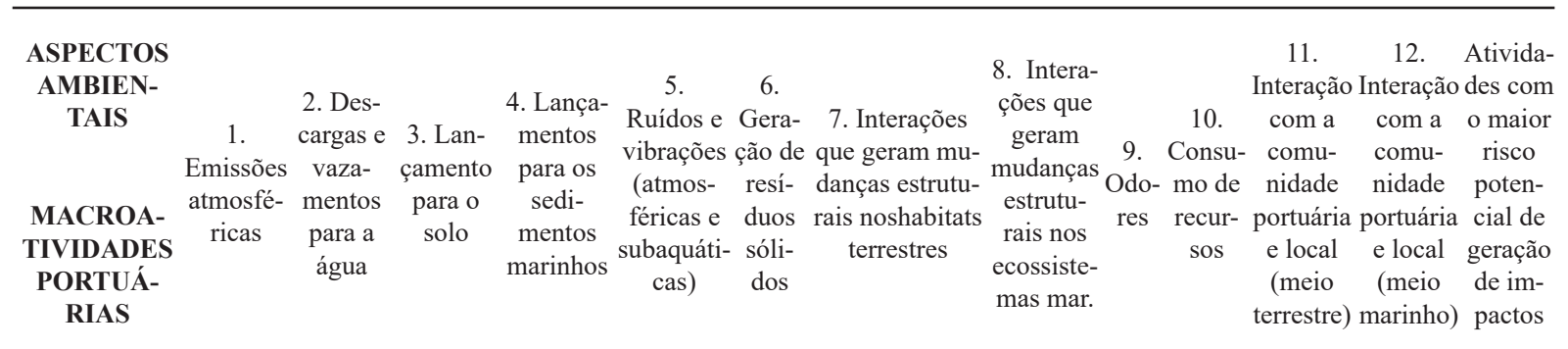

\begin{tabular}{|c|c|c|c|c|c|c|c|c|c|c|c|c|c|}
\hline $\begin{array}{l}\text { 1. Obras } \\
\text { portuárias } \\
\text { de infraest. e } \\
\text { instalações }\end{array}$ & 0 & 0 & 0 & 0 & 0 & 1 & 0 & 0 & 0 & 1 & 0 & 0 & 2 \\
\hline $\begin{array}{l}\text { 2. Dragagem } \\
\text { de manut. }\end{array}$ & 0 & 0 & 0 & 1 & 1 & 1 & 0 & 1 & 0 & 1 & 1 & 1 & 7 \\
\hline $\begin{array}{l}\text { 3. Dragagem } \\
\text { de aprof. }\end{array}$ & 0 & 0 & 0 & 0 & 0 & 0 & 0 & 0 & 0 & 0 & 0 & 0 & 0 \\
\hline $\begin{array}{l}\text { 4. Tráfego } \\
\text { marítimo }\end{array}$ & 1 & 1 & 0 & 0 & 0 & 0 & 0 & 0 & 0 & 1 & 0 & 1 & 4 \\
\hline $\begin{array}{l}\text { 5. Tráfego } \\
\text { terrestre }\end{array}$ & 1 & 0 & 1 & 0 & 1 & 0 & 0 & 0 & 0 & 1 & 1 & 0 & 5 \\
\hline $\begin{array}{l}\text { 7. Carga, desc. } \\
\text { e armaz. de } \\
\text { carga geral e } \\
\text { cont. }\end{array}$ & 0 & 0 & 0 & 0 & 0 & 0 & 0 & 0 & 0 & 1 & 1 & 0 & 2 \\
\hline $\begin{array}{l}\text { 8. Carga, des- } \\
\text { carga e armaz. } \\
\text { de granel } \\
\text { líquido }\end{array}$ & 0 & 1 & 1 & 0 & 0 & 0 & 0 & 0 & 0 & 1 & 1 & 0 & 4 \\
\hline $\begin{array}{l}\text { 9. Prov. de } \\
\text { combustível e } \\
\text { abastecimento }\end{array}$ & 0 & 0 & 0 & 0 & 0 & 1 & 0 & 0 & 0 & 1 & 1 & 0 & 3 \\
\hline
\end{tabular}


11. Recep., transporte e gestão resíd. MARPOL

\begin{tabular}{|c|c|c|c|c|c|c|c|c|c|c|c|c|c|}
\hline $\begin{array}{l}\text { 12. Recep., } \\
\text { transporte } \\
\text { e gestão de } \\
\text { águas de lastro } \\
\text { e sedimentos } \\
\text { dos navios }\end{array}$ & 0 & 1 & 0 & 1 & 0 & 0 & 0 & 1 & 0 & 0 & 0 & 0 & 3 \\
\hline $\begin{array}{l}\text { 13. Limpeza e } \\
\text { manut. de maq. } \\
\text { e instalações }\end{array}$ & 0 & 1 & 1 & 0 & 0 & 1 & 0 & 0 & 0 & 1 & 0 & 0 & 4 \\
\hline $\begin{array}{l}\text { 14. Saneamen- } \\
\text { to porto }\end{array}$ & 0 & 1 & 0 & 0 & 0 & 1 & 0 & 0 & 1 & 1 & 0 & 0 & 4 \\
\hline $\begin{array}{l}\text { 15. Ativ. indus- } \\
\text { triais }\end{array}$ & 0 & 0 & 0 & 0 & 0 & 0 & 0 & 0 & 0 & 0 & 0 & 0 & 0 \\
\hline $\begin{array}{l}\text { 18. Ativ. áreas } \\
\text { uso púb. }\end{array}$ & 0 & 0 & 0 & 0 & 1 & 1 & 0 & 0 & 0 & 0 & 1 & 1 & 4 \\
\hline $\begin{array}{l}\text { 19. Instalações } \\
\text { militares }\end{array}$ & 0 & 0 & 0 & 0 & 0 & 0 & 0 & 0 & 0 & 0 & 0 & 0 & 0 \\
\hline $\begin{array}{l}\text { 20. Func. } \\
\text { emergencial }\end{array}$ & 1 & 1 & 1 & 1 & 1 & 0 & 0 & 0 & 0 & 1 & 1 & 1 & 8 \\
\hline $\begin{array}{l}\text { 21. Serv. sanit., } \\
\text { admin. e ou- } \\
\text { tros do porto }\end{array}$ & 0 & 1 & 1 & 0 & 0 & 1 & 0 & 0 & 0 & 1 & 0 & 0 & 4 \\
\hline
\end{tabular}

FONTE: Elaboração própria com base em Asmus et al. (2015) e Scherer et al. (2015). 


\subsection{Aspectos ambientais vs. serviços ecossistêmicos}

A matriz apresentada na Tabela 3 relaciona os aspectos ambientais às unidades ambientais identificadas especificamente na área de estudo e seus respectivos serviços ecossistêmicos (provisão, suporte, regulação e cultural). Os aspectos identificados que apresentaram maior influência negativa nos serviços ecossistêmicos das unidades ambientais do porto de São Francisco do Sul foram: descargas e vazamentos para a água; lançamento para o solo (partículas e fluidos); lançamento de efluentes para os sedimentos marinhos; e a geração de resíduos sólidos. Assim como foi observado nos resultados da Tabela 2, estes aspectos não necessariamente são os que causam mais impactos ao porto e à área de seu entorno.

TABELA 3 - Aspectos ambientais vs. Serviços Ecossistêmicos no porto de São Francisco do Sul, com destaque (em cinza) aos aspectos que mais causam perda de serviços.

\begin{tabular}{|c|c|c|c|c|c|c|c|c|c|c|c|c|c|}
\hline \multirow[b]{3}{*}{$\begin{array}{c}\text { Mata } \\
\text { Atlântica }\end{array}$} & -1 & 0 & -1 & 0 & 0 & 0 & -1 & 0 & 0 & -1 & 1 & 0 & -3 \\
\hline & 0 & 0 & -1 & 0 & 0 & 0 & -1 & 0 & 0 & 0 & 0 & 0 & -2 \\
\hline & -1 & 0 & -1 & 0 & 0 & 0 & -1 & 0 & 0 & -1 & 0 & 0 & -4 \\
\hline \multirow{4}{*}{ Praias } & 0 & -1 & 0 & -1 & -1 & -1 & 0 & -1 & -1 & 0 & 0 & 0 & -6 \\
\hline & 0 & -1 & 0 & -1 & 0 & -1 & -1 & -1 & 0 & 0 & 0 & 0 & -5 \\
\hline & 0 & 0 & 0 & -1 & 0 & -1 & 0 & -1 & 0 & 0 & 0 & -1 & -4 \\
\hline & -1 & -1 & -1 & -1 & -1 & -1 & 0 & -1 & -1 & 0 & 1 & -1 & -8 \\
\hline suporte & 0 & -1 & 0 & -1 & -1 & -1 & 0 & -1 & 0 & 0 & 0 & 1 & -4 \\
\hline Canal e provisão & 0 & 0 & 0 & 0 & 0 & 0 & 0 & 0 & 0 & 0 & 0 & 0 & 0 \\
\hline $\begin{array}{cc}\begin{array}{c}\text { bacia de } \\
\text { evolução }\end{array} & \text { regula- } \\
\text { do porto } & \text { ção }\end{array}$ & 0 & -1 & 0 & -1 & 0 & -1 & 0 & -1 & 0 & 0 & 0 & 1 & -3 \\
\hline
\end{tabular}




\begin{tabular}{|c|c|c|c|c|c|c|c|c|c|c|c|c|c|c|}
\hline \multirow{4}{*}{$\begin{array}{c}\text { Berços } \\
\text { e área } \\
\text { retropor- } \\
\text { tuária }\end{array}$} & suporte & 0 & 0 & -1 & -1 & 0 & -1 & 0 & 0 & 0 & 1 & 1 & 1 & 0 \\
\hline & provisão & 0 & 0 & -1 & 0 & 0 & -1 & 0 & 0 & 0 & 1 & 0 & 0 & -1 \\
\hline & $\begin{array}{l}\text { regula- } \\
\text { ção }\end{array}$ & 0 & 0 & 0 & 0 & 0 & 0 & 0 & 0 & 0 & -1 & 1 & 0 & 0 \\
\hline & cultural & 0 & 0 & 0 & 0 & 0 & 0 & 0 & 0 & 0 & 0 & 0 & 0 & 0 \\
\hline \multirow{4}{*}{$\begin{array}{c}\text { Vias de } \\
\text { acesso ao } \\
\text { porto }\end{array}$} & suporte & -1 & 0 & -1 & 0 & -1 & 0 & -1 & 0 & 0 & -1 & 1 & 0 & -4 \\
\hline & provisão & -1 & 0 & -1 & 0 & -1 & 0 & 0 & 0 & 0 & 0 & 0 & 0 & -3 \\
\hline & $\begin{array}{l}\text { regula- } \\
\text { ção }\end{array}$ & -1 & 0 & -1 & 0 & -1 & 0 & 0 & 0 & 0 & 0 & 0 & 0 & -3 \\
\hline & cultural & 0 & 0 & 0 & 0 & 0 & 0 & 0 & 0 & 0 & 0 & 0 & 0 & 0 \\
\hline \multirow{4}{*}{$\begin{array}{l}\text { Área ur- } \\
\text { banizada }\end{array}$} & suporte & -1 & -1 & -1 & 0 & -1 & -1 & -1 & 0 & -1 & 1 & 1 & 0 & -5 \\
\hline & provisão & 0 & 0 & -1 & 0 & 0 & 0 & 0 & 0 & -1 & 1 & 1 & 0 & 0 \\
\hline & $\begin{array}{l}\text { regula- } \\
\text { ção }\end{array}$ & 0 & 0 & 0 & 0 & 0 & 0 & 0 & 0 & 0 & 1 & 1 & 0 & 2 \\
\hline & cultural & -1 & -1 & -1 & 0 & -1 & -1 & -1 & 0 & -1 & 1 & -1 & 0 & -7 \\
\hline \multirow{4}{*}{$\begin{array}{c}\text { Mangue- } \\
\text { zal }\end{array}$} & suporte & -1 & -1 & -1 & -1 & -1 & -1 & -1 & -1 & 0 & 0 & 0 & 0 & -8 \\
\hline & provisão & 0 & -1 & -1 & -1 & -1 & -1 & -1 & -1 & 0 & 0 & -1 & 0 & -8 \\
\hline & $\begin{array}{l}\text { regula- } \\
\text { ção }\end{array}$ & 0 & -1 & -1 & 0 & 0 & 0 & 0 & 0 & 0 & 0 & -1 & 0 & -3 \\
\hline & cultural & 0 & -1 & -1 & 0 & 0 & 0 & 0 & 0 & 0 & 0 & 1 & 1 & 0 \\
\hline \multirow{5}{*}{ Estuário } & suporte & 0 & -1 & 0 & -1 & -1 & -1 & 0 & -1 & 0 & 0 & 0 & 0 & -5 \\
\hline & provisão & 0 & -1 & 0 & -1 & 0 & 0 & 0 & 0 & 0 & 0 & -1 & 0 & -3 \\
\hline & & & & & & & & & & & & & & \\
\hline & $\begin{array}{l}\text { regula- } \\
\text { ção }\end{array}$ & 0 & -1 & 0 & -1 & 0 & 0 & 0 & 0 & 0 & 0 & 0 & 0 & -2 \\
\hline & cultural & 0 & -1 & 0 & -1 & -1 & -1 & 0 & 0 & 0 & 0 & 1 & 1 & -2 \\
\hline \multirow{4}{*}{$\begin{array}{l}\text { Costão } \\
\text { rochoso }\end{array}$} & suporte & 0 & -1 & 0 & -1 & 0 & 0 & -1 & -1 & 0 & 0 & 0 & -1 & -5 \\
\hline & provisão & 0 & -1 & 0 & -1 & 0 & 0 & 0 & 0 & 0 & 0 & 0 & 0 & -2 \\
\hline & $\begin{array}{l}\text { regula- } \\
\text { ção }\end{array}$ & 0 & 0 & 0 & 0 & 0 & 0 & 1 & 1 & 0 & 0 & 1 & 1 & 4 \\
\hline & cultural & 0 & -1 & 0 & -1 & 0 & -1 & 0 & 0 & 0 & 0 & 0 & 0 & -3 \\
\hline
\end{tabular}




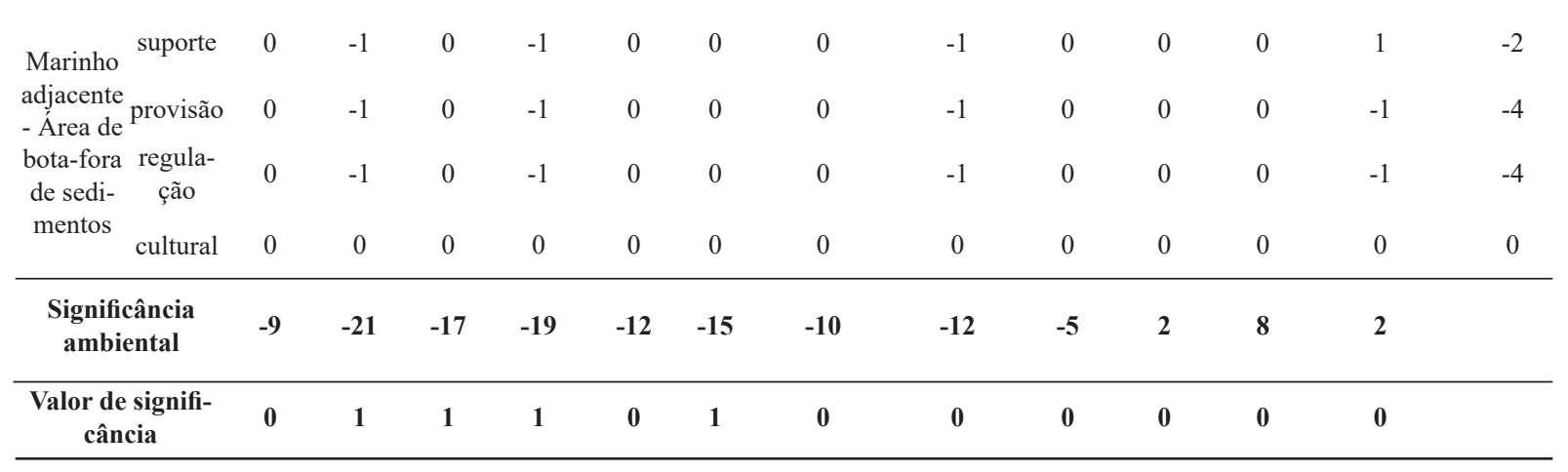

FONTE: Elaboração própria com base em Asmus et al. (2015) e Scherer et al. (2015).

\subsection{Aspectos ambientais significativos}

Os aspectos ambientais significativos foram identificados a partir da aplicação das respostas aos critérios de significância. São eles: descargas e vazamentos para a água; lançamentos de efluentes para os sedimentos marinhos; geração de resíduos sólidos; interações que geram mudanças estruturais nos ecossistemas marinhos; e interação com a comunidade portuária local (meio terrestre). Estes são os considerados significativos porque foram os aspectos que apresentaram os maiores potenciais de geração de impacto ambiental no porto de São Francisco do Sul.

\subsection{Principais impactos e indicativos de gestão}

O maior impacto causado por descargas e vazamentos para a água pode ser considerado a poluição marinha, que provoca, por exemplo, perda de habitats e contaminação dos recursos pesqueiros, afetando a saúde humana e da biota, além de prejudicar as atividades pesqueira e turística. Consequentemente, danos a estas atividades afetam também a economia local e a comunidade que depende destes serviços como fonte de renda. As unidades ambientais e seus serviços possivelmente afetados por descargas e vazamentos de água na Área do Porto Organizado de SFS e seu entorno (Tabela 5) são: praias, canal e bacia de evolução do porto, manguezal, estuário, marinho adjacente e área de bota-fora de sedimentos, e área urbanizada.

Para este aspecto, recomenda-se a implantação de sistemas de captação e tratamento das águas pluviais, da água de limpeza dos cais de atracação e das águas residuais, provenientes de atividades sanitárias e de limpeza de maquinário, além da implantação de um sistema de contenção de particulados residuais no cais de atracação. Destaca-se ainda a necessidade de maior rigidez no controle e no gerenciamento das águas de lastro dos navios.

Os lançamentos para os sedimentos marinhos podem ser causados por revolvimento de dragagem, derrame de granéis, entre outros, que percolam para o fundo, trazendo impactos para o porto, para a biota e para a comunidade. No caso de SFS, ocorre ainda o 
bota-fora de sedimentos da dragagem de manutenção do porto em área marinha. Na APO de São Francisco do Sul e no seu entorno, as unidades ambientais e seus serviços possivelmente afetados por lançamentos para os sedimentos marinhos (Tabela 6) são: praias, canal e bacia de evolução, costão rochoso e marinho adjacente, e área de bota-fora de sedimentos.

Para este aspecto, indica-se que sejam tomadas medidas de melhorias no programa de monitora- mento dos sedimentos marinhos, principalmente nas atividades de dragagem de manutenção do porto que ocorrem periodicamente, como na dragagem de aprofundamento prevista para o futuro, de forma preventiva, em vez de corretiva. E, consequentemente, especial atenção para acompanhar e minimizar os efeitos do lançamento do material de bota-fora das dragagens em meio marinho.

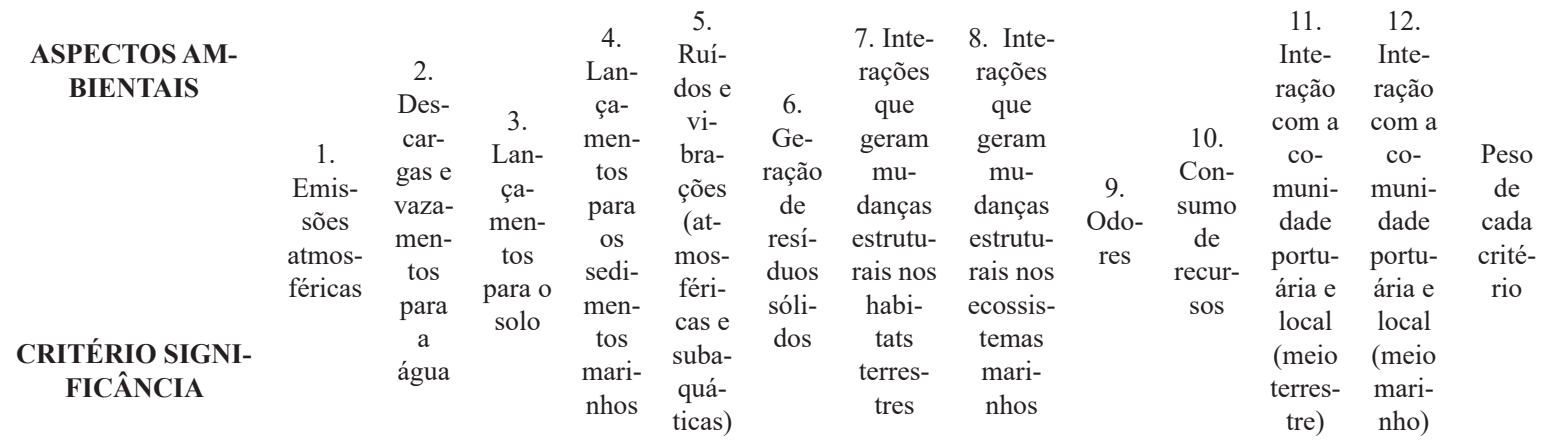

\begin{tabular}{|c|c|c|c|c|c|c|c|c|c|c|c|c|c|}
\hline $\begin{array}{l}\text { 1. Número de ativida- } \\
\text { des envolvidas. }\end{array}$ & 0 & 1 & 0 & 0 & 0 & 1 & 0 & 0 & 0 & 1 & 1 & 0 & 4 \\
\hline $\begin{array}{l}\text { 2. Perda/ganho de } \\
\text { um } \mathrm{n}^{\circ} \text { signif. de serv. } \\
\text { ecossist. e ambientais. }\end{array}$ & 0 & 1 & 1 & 1 & 0 & 1 & 0 & 0 & 0 & 0 & 0 & 0 & 4 \\
\hline $\begin{array}{l}\text { 3. Afeta/pode afetar } \\
\text { as ativ. ou uso p/ o } \\
\text { munic. e unid. amb. }\end{array}$ & 0 & 1 & 0 & 0 & 0 & 1 & 0 & 1 & 0 & 0 & 1 & 1 & 5 \\
\hline $\begin{array}{l}\text { 4. Histórico ou risco } \\
\text { de acidentes pela } \\
\text { natureza da ativ. }\end{array}$ & 1 & 1 & 0 & 1 & 0 & 0 & 0 & 1 & 0 & 0 & 0 & 1 & 5 \\
\hline $\begin{array}{l}\text { 5. Reclam. cid. e/ } \\
\text { ou dos trab. do porto } \\
\text { / prioridade agenda } \\
\text { local. }\end{array}$ & 0 & 1 & 0 & 1 & 1 & 0 & 0 & 1 & 0 & 0 & 1 & 1 & 6 \\
\hline
\end{tabular}




\begin{tabular}{|c|c|c|c|c|c|c|c|c|c|c|c|c|c|}
\hline $\begin{array}{l}\text { 6. Alcance multiesca- } \\
\text { lar (consumo energia } \\
\text { e água) }\end{array}$ & 1 & 0 & 0 & 0 & 0 & 1 & 0 & 0 & 0 & 1 & 0 & 0 & 3 \\
\hline $\begin{array}{l}\text { 7. Identificado pelo } \\
\text { porto e arrendatários } \\
\text { como asp. signif. }\end{array}$ & 0 & 1 & 0 & 1 & 0 & 1 & 0 & 1 & 0 & 0 & 1 & 0 & 5 \\
\hline $\begin{array}{l}\text { Significância am- } \\
\text { biental }\end{array}$ & 2 & 6 & 1 & 4 & 1 & 5 & $\mathbf{0}$ & 4 & $\mathbf{0}$ & 2 & 4 & 3 & \\
\hline
\end{tabular}

FONTE: Elaboração própria com base em Asmus et al. (2015) e Scherer et al. (2015).

A geração de resíduos sólidos pode ter origem nas atividades portuária e urbana, prejudicando o meio ambiente, a sociedade e sua economia, ao atingir, por exemplo, a atividade turística, a qualidade da água, os habitats e os recursos naturais. A gestão dos resíduos portuários sólidos em SFS passou de "crítica" a "excelente" entre março de 2009 e fevereiro de 2010, quando foi implementado o plano de gerenciamento para o porto (Baptista, 2014). Porém, sabe-se que são necessárias contínua avaliação e melhoria do programa para o seu bom funcionamento. As unidades ambientais e seus serviços afetados pela geração de resíduos sólidos na APO de São Francisco do Sul e no seu entorno (Tabela 7) foram: praias, canal e bacia de evolução do porto, berços e área retroportuária, manguezal, estuário, marinho adjacente e área de bota-fora de sedimentos, e área urbanizada.

Sobre este aspecto, é recomendada a realização de avaliação e melhoria do programa de gestão de

TABELA 5 - Impactos causados pelas descargas e vazamentos para a água no porto de São Francisco do Sul.

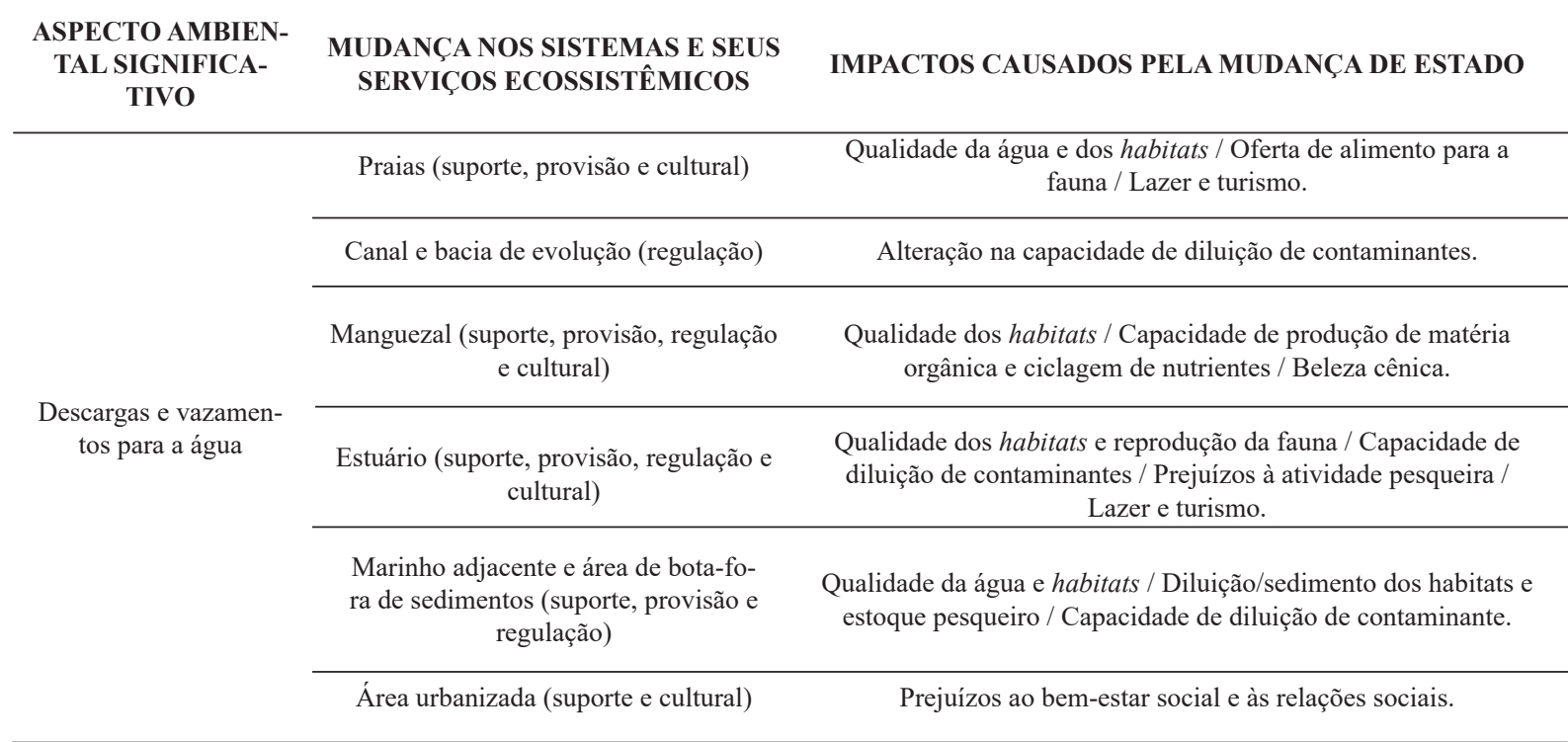

FONTE: Elaboração própria com base em Asmus et al. (2015) e Scherer et al. (2015). 
resíduos sólidos originários da atividade portuária e do sistema de controle e monitoramento dos resíduos da dragagem de manutenção. Mesmo que o porto tenha passado por melhorias na implementação do programa de gestão de resíduos, faz-se necessário contínuo monitoramento das atividades, especialmente devido à importância da manutenção da qualidade dos ecossistemas da região. $\mathrm{O}$ responsável pela gestão ambiental portuária destacou a boa relação com a gestão municipal. Assim, uma forma de o porto auxiliar envolveria seu apoio à gestão do saneamento básico do município de São Francisco do Sul.

$\mathrm{O}$ aspecto de interações que geram mudanças estruturais nos ecossistemas marinhos pode ser causado por atividades de dragagem, interferência em áreas de proteção ambiental, estrutura geral do porto, entre outros fatores, acarretando danos diretamente à saúde da biota $\mathrm{e}$, consequentemente, à comunidade também. Na APO de São Francisco do Sul e no seu entorno, os ecossis- temas e seus serviços influenciados por interações que geram mudanças estruturais nos ecossistemas marinhos (Tabela 8) foram: praias, canal e bacia de evolução do porto, manguezal, estuário, costão rochoso, e marinho adjacente e área de bota-fora de sedimentos.

Tratando deste aspecto, as recomendações são também acerca do monitoramento das atividades de dragagem, além de cuidados com o tráfego marítimo e com o planejamento das obras portuárias e seus respectivos impactos ambientais. O projeto Babitonga Ativa destacou principais impactos e diretrizes direcionados aos interesses dos agentes portuários (UNIVILLE, 2017). Recomenda-se a devida aplicação das diretrizes e protocolos de atuação para a atividade portuária, assim como de gestão do tráfego marítimo frente às ameaças para os ecossistemas envolvidos.

Finalmente, o aspecto de interação com a comunidade portuária local (meio terrestre) pode estar relacionado às atividades de intenso tráfego terrestre rodoviário e ferroviário, à emissão de particulados,

TABELA 6 - Impactos causados pelos lançamentos para os sedimentos marinhos no porto de São Francisco do Sul.

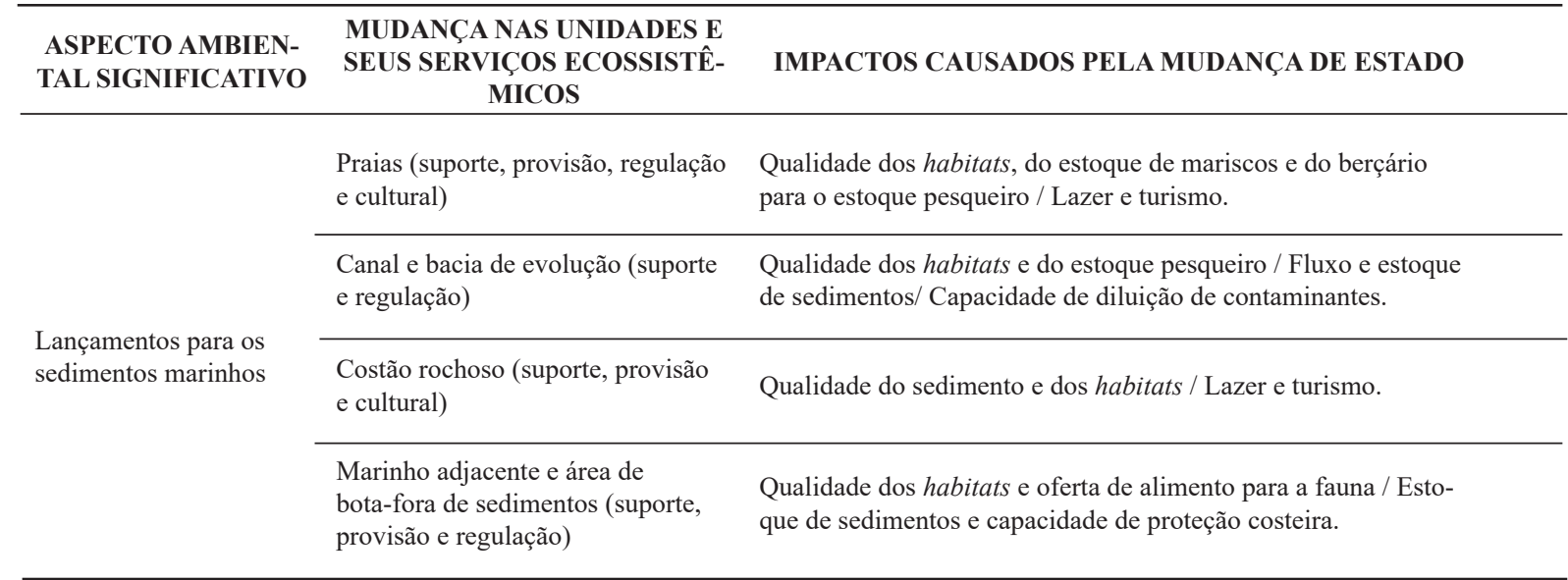

FONTE: Elaboração própria com base em Asmus et al. (2015) e Scherer et al. (2015). 
aos odores e ruídos, à estrutura geral do porto, além de geração de emprego e renda ao município. Estes fatores geram diversos conflitos na relação porto-cidade, que devem ser tratados da melhor maneira possível visando ao bem-estar comum das partes. As unidades ambientais e seus serviços afetados pela interação com a comunidade portuária local (meio terrestre) na APO de São Francisco do Sul e no seu entorno (Tabela 9) foram: praias, manguezal, estuário, área retroportuária, vias de acesso ao porto e área urbanizada.

Quanto a este aspecto, recomenda-se a implementação de projetos com ativa participação social sobre a percepção do porto, por exemplo, programas de educação ambiental, de ouvidoria da comunidade, pescadores artesanais e turistas. O Porto de SFS comprometeu-se, como uma das condicionantes de sua Licença de Operação, com a remoção de uma comunidade (Bela Vista) do entorno portuário, fato que motiva diversos conflitos de interesse na área. É necessária a participação direta da sociedade nas medidas que decidirão este caso, de forma a incluir não apenas interesses econômicos, mas as necessidades das partes como um todo.

TABELA 7 - Impactos causados pela geração de resíduos sólidos no porto de São Francisco do Sul.

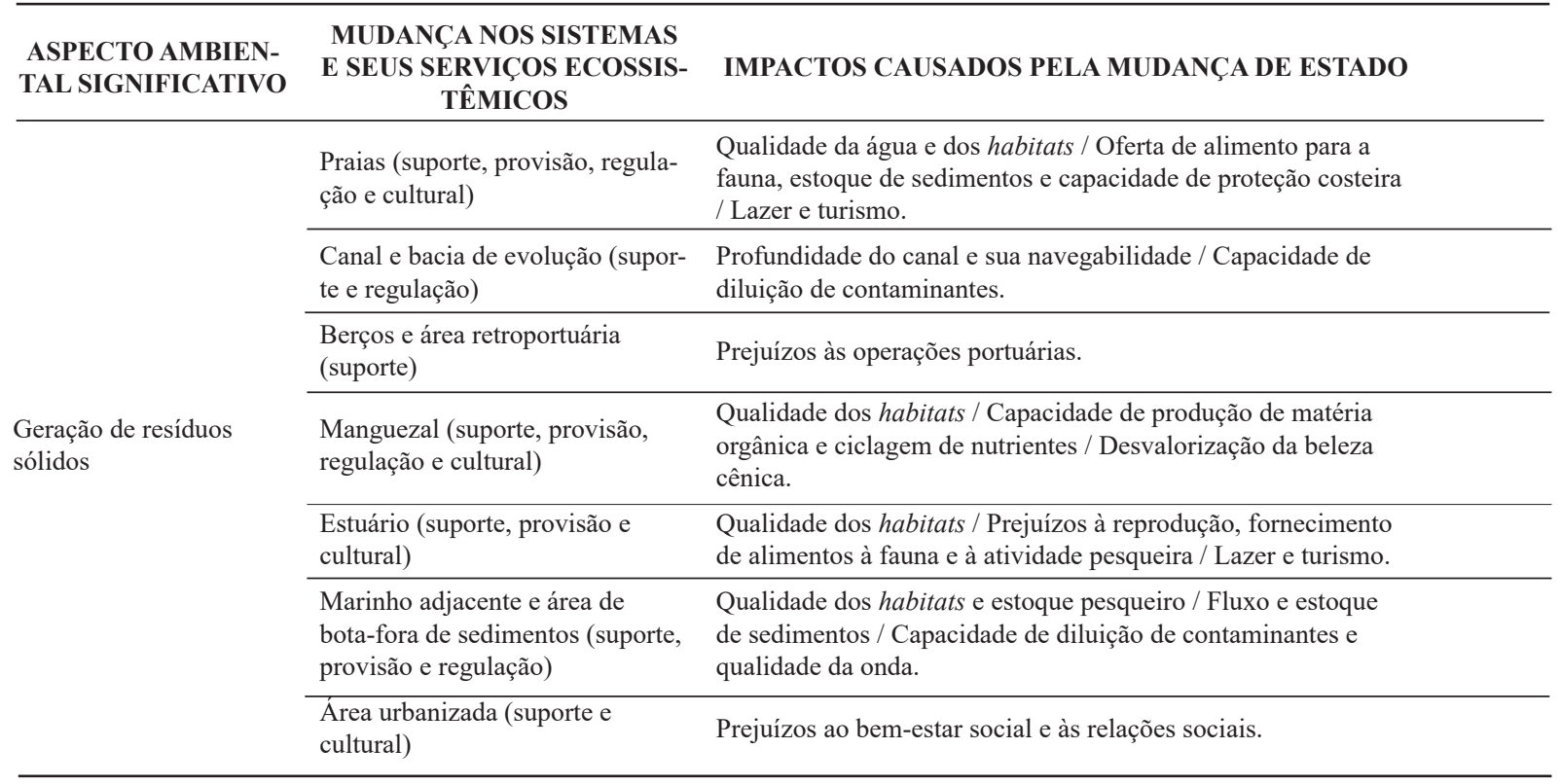

FONTE: Elaboração própria com base em Asmus et al. (2015) e Scherer et al. (2015). 
TABELA 8 - Impactos causados pelas interações que geram mudanças estruturais nos ecossistemas marinhos causados pelo porto de São Francisco do Sul.

\begin{tabular}{|c|c|c|}
\hline $\begin{array}{l}\text { ASPECTO AMBIEN- } \\
\text { TAL SIGNIFICATIVO }\end{array}$ & $\begin{array}{l}\text { MUDANÇA NOS SISTE- } \\
\text { MAS E SEUS SERVIÇOS } \\
\text { ECOSSISTÊMICOS }\end{array}$ & IMPACTOS CAUSADOS PELA MUDANÇA DE ESTADO \\
\hline
\end{tabular}

\begin{tabular}{lll} 
& $\begin{array}{l}\text { Praias (suporte, provisão, } \\
\text { regulação e cultural) }\end{array}$ & $\begin{array}{l}\text { Qualidade da água e dos habitats / Oferta de alimento para a fauna, esto- } \\
\text { que de sedimentos e capacidade de proteção costeira / Lazer e turismo. }\end{array}$ \\
\cline { 2 - 3 } $\begin{array}{l}\text { Interações que geram } \\
\text { mudanças estruturais nos } \\
\text { ecossistemas marinhos }\end{array}$ & $\begin{array}{l}\text { Canal e bacia de evolução } \\
\text { (suporte e regulação) }\end{array}$ & $\begin{array}{l}\text { Navegabilidade e capacidade de diluição de contaminantes/ Qualidade } \\
\text { da biota }\end{array}$ \\
\cline { 2 - 3 } & $\begin{array}{l}\text { Estuário (suporte, provisão, } \\
\text { regulação e cultural) }\end{array}$ & $\begin{array}{l}\text { Qualidade dos habitats / Prejuízos à reprodução e fornecimento de } \\
\text { alimentos à fauna / Prejuízos à atividade pesqueira. }\end{array}$ \\
\cline { 2 - 3 } & $\begin{array}{l}\text { Costão rochoso (suporte, pro- } \\
\text { visão, regulação e cultural) }\end{array}$ & $\begin{array}{l}\text { Qualidade dos habitats / Possível melhoria na capacidade de abrigo, do do } \\
\text { estoque de mariscos e do berçário para o estoque pesqueiro / Prejuízos às } \\
\text { atividades de lazer e turismo. }\end{array}$ \\
\cline { 2 - 3 } & $\begin{array}{l}\text { Marinho adjacente e área de } \\
\text { bota-fora de sedimentos (su- } \\
\text { porte, provisão e regulação) }\end{array}$ & $\begin{array}{l}\text { Capacidade de diluição de contaminantes / Prejuízos à atividade pesquei- } \\
\text { ra. }\end{array}$ \\
\hline
\end{tabular}

FONTE: Elaboração própria com base em Asmus et al. (2015) e Scherer et al. (2015).

TABELA 9 - Impactos causados pela interação com a comunidade portuária local (meio terrestre) no porto de São Francisco do Sul.

\begin{tabular}{|c|c|c|}
\hline $\begin{array}{l}\text { ASPECTO AMBIEN- } \\
\text { TAL SIGNIFICA- } \\
\text { TIVO }\end{array}$ & $\begin{array}{l}\text { MUDANÇA NAS UNIDADES E } \\
\text { SEUS SERVIÇOS ECOSSISTÊMI- } \\
\text { COS }\end{array}$ & $\begin{array}{l}\text { IMPACTOS CAUSADOS PELA MUDANÇA DE } \\
\text { ESTADO }\end{array}$ \\
\hline \multirow{5}{*}{$\begin{array}{l}\text { Interação com a comu- } \\
\text { nidade portuária local } \\
\text { (meio terrestre) }\end{array}$} & Praias (cultural) & Desvalorização das práticas de lazer e turismo \\
\hline & $\begin{array}{l}\text { Estuário (suporte, provisão, regulação } \\
\text { e cultural) }\end{array}$ & $\begin{array}{l}\text { Qualidade dos habitats / Reprodução e fornecimento de } \\
\text { alimentos à fauna / Prejuízos à atividade pesqueira. }\end{array}$ \\
\hline & Manguezal (provisão e cultural) & $\begin{array}{l}\text { Prejuízos à reprodução, à capacidade para berçário de } \\
\text { espécies e à atividade pesqueira }\end{array}$ \\
\hline & $\begin{array}{l}\text { Área retroportuária (suporte e regula- } \\
\text { ção) }\end{array}$ & $\begin{array}{l}\text { Qualidade dos habitats / Prejuízos à reprodução e à capa- } \\
\text { cidade para berçário de espécies. }\end{array}$ \\
\hline & Área urbanizada (suporte e cultural) & Prejuízos ao bem-estar social e às relações sociais. \\
\hline
\end{tabular}

FONTE: Elaboração própria com base em Asmus et al. (2015) e Scherer et al. (2015). 
Destaca-se a necessidade, por parte do Governo, de entrega das obras de acesso terrestre (rodoviário e ferroviário) que trariam melhorias na relação porto-cidade, na logística de entrada e saída de caminhões e material no porto, e na sinalização e no controle de tráfego terrestre. Finalmente, recomenda-se o desenvolvimento de um sistema de monitoramento de reclamações da comunidade local (especialmente pescadores artesanais) e dos trabalhadores portuários.

TABELA 10 - Compilação dos resultados associados ao modelo DPSIR para o porto de São Francisco do Sul.

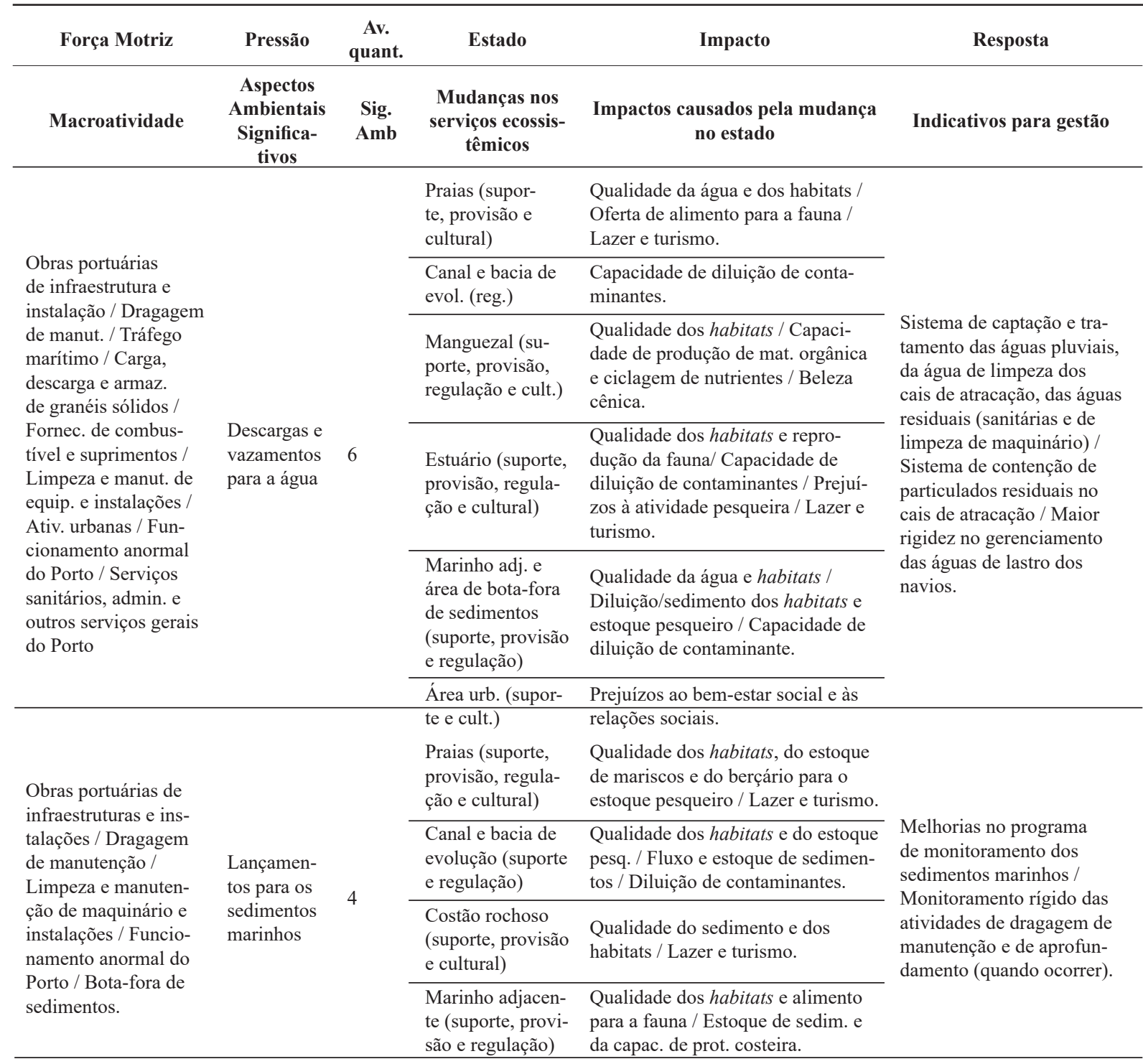


Obras portuárias de infraestruturas e instalações / Dragagem de manutenção/ Fornec. de combustíveis e peza e manutenção de maquinários e instalações / Atividades urbanas / Atividades em áreas de uso público / Funcionamento anormal do Porto / Serviços sanitários, administrativos e outros serviços gerais do Porto. abastecimento / Lim-

Praias (suporte, provisão, regulação e cultural)

Qualidade da água e dos habitats / Alimento para a fauna, estoque seCost. / Lazer e turismo. evolução (suporte gabilidade / Capacidade de diluição e regulação) de contaminantes.

Berços e área ret. (suporte)

Prejuízos às operações portuárias.

Geração de resíduos sólidos

Manguezal (suporte, provisão, regulação e cult.)

Qualidade dos habitats / Produção de matéria orgânica e ciclagem de nutrientes / Beleza cênica.

Estuário (suporte, Qualidade dos habitats / Prejuízos provisão e cul- à reprod., fornec. de alim. à fauna e tural) ativ. pesqueira / Lazer e turismo.

Mar. adj. e área de bota-fora de sedimentos (suporte, provisão e regulação)

Área urb. (suporte e cult.)

Qualidade dos habitats e o estoque pesqueiro / Fluxo e estoque de sedimentos / Capacidade de diluição de contaminantes e da qualidade da onda.

Prejuízos ao bem-estar social e às relações sociais.

Praias (suporte, provisão, regulação e cultural)

Qualidade da água e dos habitats / Alim. p/ fauna, estoque de sedim. e capac. de prot. cost./ Lazer e turismo.

Canal e bacia de Navegabilidade e capacidade de dievolução (suporte luição de contaminantes/ Qualidade e regulação) da biota

Obras portuárias de infraestruturas e instalações / Dragagem de manutenção / Tráfego marítimo / Atividades urbanas / Bota-fora de sedimentos / Funcionamento anormal do Porto.
Interações que geram mudanças estruturais nos ecossistemas marinhos
Avaliação e melhoria do programa de gestão de resíduos sólidos originários da atividade portuária / Melhoria do sistema de controle e monitoramento dos resíduos da dragagem de manutenção (bota-fora em área marinha) / Apoio ao saneamento básico do município.
Monitoramento das atividades de dragagem / Planejamento das obras portuárias e de seus impactos ambientais / Diretrizes e protocolos de atuação para a atividade portuária / Gestão do tráfego marítimo frente às ameaças para os ecossistemas.
Costão rochoso (suporte, provisão, regulação e cultural)

Marinho adjacente (suporte, provisão e regulação)
Qualidade dos habitats / Possíve melhoria na capac. de abrigo, do estoque de mariscos e do berçário para o estoque pesqueiro / Prejuízos ao lazer e ao turismo.

Capacidade de diluição de contaminantes / Prejuízos à atividade pesqueira. 
Obras portuárias de infraestruturas e instalações / Dragagem de manutenção / Atividades em áreas de uso público / Carga, descarga e armazenamento de granéis sólidos, líquidos e carga geral / Funcionamento anormal do Porto

\begin{tabular}{|c|c|c|c|c|}
\hline \multirow{6}{*}{$\begin{array}{l}\text { Interação } \\
\text { com a } \\
\text { comunidade } \\
\text { portuária } \\
\text { local (meio } \\
\text { terrestre) }\end{array}$} & \multirow{6}{*}{4} & Praias (cultural) & $\begin{array}{l}\text { Desvalorização da prática de lazer } \\
\text { e turismo }\end{array}$ & \multirow{6}{*}{$\begin{array}{l}\text { Proj. ativos de partic. social } \\
\text { (ed. ambiental, ouvidoria, } \\
\text { pescadores, turistas) / } \\
\text { Comunidade Bela Vista / } \\
\text { Obras de infraest. rod. e } \\
\text { fer. (melhorias na logística } \\
\text { de entrada e saída de ca- } \\
\text { minhões/material no porto; } \\
\text { melhorias na sinalização } \\
\text { e no controle de tráfego } \\
\text { terrestre) / Monit. de recla- } \\
\text { mações da comunidade e } \\
\text { trab. do porto; }\end{array}$} \\
\hline & & $\begin{array}{l}\text { Estuário (suporte, } \\
\text { provisão, regula- } \\
\text { ção e cultural) }\end{array}$ & $\begin{array}{l}\text { Qualidade dos habitats / Prejuízos } \\
\text { à reprod., fornec. de alimentos à } \\
\text { fauna e à atividade pesqueira. }\end{array}$ & \\
\hline & & $\begin{array}{l}\text { Manguezal (pro- } \\
\text { visão e cultural) }\end{array}$ & $\begin{array}{l}\text { Prejuízos à reprodução e à capa- } \\
\text { cidade para berçário de espécies / } \\
\text { Prejuízos à atividade pesqueira }\end{array}$ & \\
\hline & & $\begin{array}{l}\text { Área retropor- } \\
\text { tuária (suporte e } \\
\text { regulação) }\end{array}$ & $\begin{array}{l}\text { Qualidade dos habitats / Prejuízos } \\
\text { à reprodução e à capacidade para } \\
\text { berçário de espécies. }\end{array}$ & \\
\hline & & $\begin{array}{l}\text { Vias de acesso ao } \\
\text { porto (suporte e } \\
\text { regulação) }\end{array}$ & $\begin{array}{l}\text { Capacidade de acesso terrestre pela } \\
\text { comunidade / Acumula reclamações } \\
\text { da comunidade }\end{array}$ & \\
\hline & & $\begin{array}{l}\text { Área urb. (supor- } \\
\text { te e cult.) }\end{array}$ & $\begin{array}{l}\text { Prejuízos ao bem-estar social e às } \\
\text { relações sociais. }\end{array}$ & \\
\hline
\end{tabular}

FONTE: Elaboração própria com base em Asmus et al. (2015) e Scherer et al. (2015).

\subsection{Modelo "Drivers-Pressure-State-Impact- Responce" (DPSIR)}

Pode-se considerar que o modelo DPSIR apresenta os indicadores necessários para proporcionar o devido suporte aos representantes políticos sobre a qualidade ambiental e o impacto resultante das escolhas políticas feitas, ou a serem feitas no futuro (Kristensen, 2004). A metodologia utilizada neste trabalho propôs, para o caso da atividade portuária, na prática, que sejam utilizados os dados resultantes da aplicação dos quadros e matrizes que tornam possível a identificação tanto dos impactos já presentes no porto quanto dos possíveis impactos e medidas de resposta a eles. Dessa forma, desenvolveu-se um trabalho baseado no princípio da prevenção, sabendo que muitos dos impactos ambientais causados pela atividade portuária podem ser evitados, e procurou-se o desenvolvimento de medidas que os impeçam ou minimizem antes que ocorram.

Para tal, destacam-se os dados obtidos por meio do preenchimento de todos os quadros apre- sentados neste estudo, na forma de uma compilação dos resultados apresentados na Tabela 10, que relaciona os fatores portuários significantes de São Francisco do Sul aos seus respectivos representantes do modelo DPSIR. Estes fatores são as atividades portuárias (forças motrizes) associadas aos aspectos ambientais significativos (pressões), o valor dessa significância segundo os resultados da Tabela 4, quais unidades ambientais e seus respectivos serviços sofrem algum tipo de alteração devido às atividades e aos aspectos do porto (estado), que tipo de impactos estas mudanças podem causar (impacto) e a proposta de quais medidas podem ser adotadas para minimizar os impactos e estabelecer um ciclo de melhoria contínua estre as relações Porto vs. Ambiente e Porto vs. Comunidade.

\section{Considerações finais}

A atividade humana tem interferido profundamente no meio ambiente nas últimas décadas, 
e a perda de fluxos dos serviços ecossistêmicos é preocupante, uma vez que replicar os serviços fornecidos pelos sistemas naturais é tarefa complexa, cara ou mesmo impossível (Resende, 2014). No setor portuário, estratégias de gestão ambiental sempre foram vistas como custo adicional. Porém, essa lógica vem sendo aos poucos substituída pela ideia de que a preservação ambiental é um fator de vantagem competitiva sustentável, principalmente quando relacionada às ações de responsabilidade social corporativa (Kitzmann \& Asmus, 2006).

O porto de SFS já possui programas de monitoramento e gerenciamento de resíduos, da biota, de educação ambiental, entre outros. Tais programas visam "garantir que as operações portuárias sejam realizadas com respeito ao meio ambiente por meio da implantação de programas que garantam a prevenção da poluição e a melhoria contínua atendendo a legislação ambiental aplicável" (APSFS, 2016a). No entanto, ainda há falhas na aplicação de políticas portuárias que contemplem a sociedade e o meio ambiente de forma adequada. Apesar da preocupação em atender demandas de preservação ambiental, muitas vezes esses programas têm por finalidade somente obter dados ambientais, sem realmente tomar medidas de conservação ou até de mitigação de danos. Da mesma forma, são considerados incipientes para as necessidades da área de estudo, que é valiosa não só pelos seus aspectos ambientais, mas também pelos aspectos social, histórico e cultural.

Não obstante, o porto de São Francisco do Sul é um dos mais bem colocados do Brasil em relação às questões ambientais. Ele está localizado numa região que apresenta diversas áreas protegidas, por ser considerada de grande importância para a preservação ambiental. Essa característica pode ser um fator positivo para a conservação dos ecossistemas e a manutenção de uma boa relação entre o meio ambiente, a atividade portuária e a sociedade. Para isso, é necessária a aplicação das medidas para gestão e monitoramento das Unidades Ambientais, das macroatividades e dos aspectos ambientais em destaque. Este monitoramento deve ser contínuo, visto que há constantes mudanças nas macroatividades portuárias e seus aspectos. Deste modo, tais fatores podem provocar outros impactos em diferentes ecossistemas, necessitando de estratégias de resposta também diferenciadas.

Assim, a metodologia aqui apresentada leva em consideração os fatores sociais, ecológicos e econômicos do porto de São Francisco do Sul, a partir da análise ecossistêmica, buscando, além da manutenção dos ecossistemas, a melhoria da qualidade de vida e o bem-estar humano da comunidade portuária e do entorno. A abordagem proposta permitiria uma melhoria dos programas ambientais já existentes, objetivando um avanço contínuo nas medidas tomadas para o porto de São Francisco do Sul por meio de seu Sistema de Gestão Ambiental. É imprescindível que o Sistema de Gestão Ambiental seja de fato eficaz e não simplesmente uma "obrigação" para o cumprimento de legislação ambiental presente neste e em outros portos brasileiros.

\section{Referências}

ANTAQ - Agência Nacional de Transporte Aquaviário. Ranking Índice de Desempenho Ambiental (IDA) $1^{\circ}$ sem./2016. Disponível em: <http://portal.antaq.gov.br/ wp-content/uploads/2017/03/ranking-ida-primeiro-semestre-de-2016.pdf>. Acesso em: fev. 2018.

APSFS - Administração do Porto de São Francisco do Sul. Informações: Programas ambientais. Disponível em: 
$<$ http://www.apsfs.sc.gov.br/?page_id=529>. Acesso em: abr. 2016a.

APSFS - Administração do Porto de São Francisco do Sul. Institucional: Características físicas. Disponível em: $<$ http://www.apsfs.sc.gov.br/?page_id=505>. Acesso em: abr. 2016 b.

Arkemal, K. K.; Abramson, S. C.; Dewsbury, B. M. Marine ecosystem-based management: from characterization to implementation. Frontiers in Ecology and the Environment., 4(10), 525-532, 2006. doi: 10.1890/1540-9295(2006)4[525:MEMFCT]2.0.CO;2

Asmus, M. L.; Scherer, M. G.; Garcia, J.; Abrahão, G. R. Gestión basada en ecosistemas para sistemas portuarios: Una propuesta metodológica para integrar la gestión de zonas costeras en Brasil. In: Anais del XVI Congreso Latinoamericano de Ciencias del Mar-COLACMAR. Santa Marta, Colombia, out. 2015.

Baptista, T. Implantação do Plano de Gerenciamento de Resíduos Sólidos no Porto de São Francisco do Sul. Revista Meio Ambiente e Sustentabilidade, 6(3), 2014. Disponível em: $<$ https://www.uninter.com/revistameioambiente/index. php/meioAmbiente/article/view/185/121>. Acesso em: nov. 2016.

Barragán, J. M. (Coord.). Manejo Costero Integrado y Política Pública en Iberoamérica: Un diagnóstico. Necesidad de Cambio. Cádiz: Red IBERMAR, 2010.

Berger F. R. Portos e terminais maritimos do Brasil. Joinville: Bela Catarina, 2006.

Cabral, E. B. Estudo geográfico do porto de São Francisco do Sul e do terminal de Itapóa-SC. Florianópolis, Dissertação (Mestrado em Geografia) - UFSC, 2011.

Costa, F. M. B. M. D. da. Plano de Desenvolvimento e Zoneamento (PDZ) do Porto de São Francisco do Sul - volumes I II. Secretaria Nacional de Portos, 2011. Disponível em: <http://www.portosdobrasil.gov.br/assuntos-1/gestao/ poligonais/sao-francisco-do-sul/plano-de-desenvolvimento-e-zoneamento-pdz-do-porto-sfs-2011.pdf > . Acesso em: dez. 2015.

Cremer, M. J.; Moraes, P. R. D.; Oliveira, T. M. N. Diagnóstico Ambiental da Baía da Babitonga. Joinville: Univille,
2006.

EEA - European Environment Agency. Environmental indicators: Typology and overview. Technical report N.25. Copenhagen, 1999.

García-Onetti, J. Servicios ecosistémicos y gobernanza de sistemas portuarios. Tese apresentada por Javier García Onetti para a obtenção do título de doutor, em regime de cotutela, pelo Programa de Doutorado em Gestão e Conservação do Mar da Escola Internacional de Doutorado em Estudos do Mar, EIDEMAR (Universidade de Cádiz, Espanha) e pelo Programa de Pós-graduação em Geografia (Universidade Federal de Santa Catarina, Brasil). 2017

García-Onetti, J.; Scherer, M. E. G.; Barragán, J. M. Integrated and ecosystemic approaches for bridging the gap between environmental management and port management. Journal of Environmental Management, 206, 615e624, 2018. doi: 10.1016/j.jenvman.2017.11.004

Hesp, P. A.; Short, A. D. Barrier morphodynamics. In: Short, A. D. (Ed.). Handbook of beach and shoreface morphodynamics. Chichester: John Willey \& Sons, 1999. p. 307-333.

IBGE - Instituto Brasileiro de Geografia e Estatística. Resultados de Características Gerais da População. Censo Demográfico 2010. Disponível em: <http://cidades.ibge. gov.br/v4/brasil/sc/sao-francisco-do-sul/panorama $>$. Acesso em: 13 jan. 2017.

INPE - Instituto Nacional de Pesquisas Espaciais. ATLAS, Fundação SOS Mata Atlântica, 2016. Disponível em: $<$ http://mapas.sosma.org.br/>. Acesso em: dez. 2016.

Kitzmann, D. I. S.; Asmus, M. L. Gestão ambiental portuária: desafios e possibilidades. Revista de Administração Pública-RAP, 40(6), 1041-1060, 2006.

Kristensen, P. The DPSIR Framework. Paper presented at the 27-29 September 2004 workshop on a comprehensive/ detailed assessment of the vulnerability of water resources to environmental change in Africa using river basin approach. UNEP. Nairobi, 2004.

LABTRANS - Laboratório de Transportes e Logística. Plano Mestre do Porto de São Francisco do Sul. Secretaria de Portos da Presidência da República e Universidade Federal de Santa Catarina. Florianópolis, 2012. 
Lima, A. Interação de fatores físicos e humanos na ocupação de zonas costeiras: o caso de São Francisco do Sul/ SC. Florianópolis/SC, Dissertação (Mestrado) - Programa de Pós-Graduação em Geografia da Universidade Federal de Santa Catarina, 2016.

Lourenço A. V. Diretrizes para um Plano de Gestão Ambiental Portuário contextualizado nos estágios do Ciclo do GCI. Estudo de caso no Porto do Rio Grande. Rio Grande, Dissertação (Mestrado em Gerenciamento Costeiro) - FURG, 2012. Disponível em: <http://repositorio.furg.br:8080/ handle/1/4019>. Acesso em: nov. 2015.

Mancini, L. A. Turismo Cultural: Proposta de Roteiro Interpretativo para o município de São Francisco do Sul - SC. Balneário Camboriú, Dissertação (Mestrado em Turismo e Hotelaria) - UNIVALI, 2007.

MEA - Millennium Ecosystem Assessment. Ecosystem and Human Well-Being: A framework for assessment. Washington, DC: Island Press, 2003.

Porto, M. M.; TEIXEIRA, S. G. Portos e Meio Ambiente. São Paulo: Aduaneiras, 2002.

Press, F.; Siever, R.; Grotzinger, J.; Jordan, T. H. Para entender a Terra. 4. ed. Porto Alegre: Bookman, 2006.

Resende, F. M.; Fernandes, G. W.; Andrade, D. C. A perigosa deterioração dos serviços de ecossistemas. Scientific American Brasil, 140, 70-75, 2014.

Schaeffer-Novelli, Y. (Coord.). Manguezal: Ecossistema entre a Terra e o Mar. São Paulo: Caribbean Ecological Research, 1995.
Scherer, M.; Asmus, M. L.; García-Onetti, J. Metodologia para identificação, com base ecossistêmica, dos aspectos e impactos ambientais significativos do Porto de Imbituba: Manual de aplicação. Relatório Técnico. Laboratório de Gerenciamento Costeiro (LAGECI), UFSC, 2015.

Scherer, M.; Asmus, M. L. Ecosystem-Based Knowledge and Management as a tool for Integrated Coastal and Ocean Management: A Brazilian Initiative. In: Vila-Concejo, A.; Bruce, E.; Kennedy, D. M.; McCarroll, R. J. (Eds.). Proceedings of the 14th International Coastal Symposium (Sydney, Australia). Journal of Coastal Research, Special Issue, 75(1), 690-694, 2016. doi: 10.2112/SI75-138.1

Slocombe, S. Defining Goals and Criteria for Ecosystem-Based Management. Environmental Management, 22(4), 483-493, 1998.

UNIVILLE. Babitonga Ativa. Resultados das Reunioes com usuários diretos do Ecossistema Babitonga para Mapeamento de usos e conflitos. Setor: Agentes De Transporte Aquaviário. Pró-Reitoria de Extensão e Assuntos Comunitários, Univille. Joinville, 2017. Disponível em: $<$ https://drive.google.com/drive/folders/0B6smVTdRc6iRVG14N29sZzhfUEk>. Acesso em: 24 abr. 2017.

Vieira, C. V. Evolução geológica da planície costeira do extremo norte da ilha de São Francisco do Sul, Santa Catarina, Brasil. Florianópolis, Tese (Doutorado em Geografia) - UFSC, 2016. 